\title{
OUTSOURCING AND TRADE IN A SPATIAL WORLD
}

\author{
HARTMUT EGGER \\ PETER EGGER
}

CESIFO WORKING PAPER No. 1349

CATEGORY 7: TRAdE POLICY

DECEMBER 2004

An electronic version of the paper may be downloaded

- from the SSRN website:

www.SSRN.com

- from the CESifo website:

www. CESifo.de 


\title{
OUTSOURCING AND TRADE IN A SPATIAL WORLD
}

\begin{abstract}
This paper provides an analysis of outsourcing and trade in a spatial model à la Hotelling. In this setting, we discuss the trade-off between transport-cost-related disadvantages and outsourcing-induced production cost advantages of a large economy. The model gives a rich picture of possible trade and welfare effects of a movement towards free trade and points to the role of national transport costs for explaining these effects. Moreover, it gives economic insights in the countries' incentives to lower tariffs and to participate in free trade agreements with partner countries that differ in size and economic capacity.
\end{abstract}

JEL Code: F12, F15, L13.

Keywords: international outsourcing, international trade, spatial competition.

\author{
Hartmut Egger \\ University of Zurich \\ Socioeconomic Institute \\ Department of Economics \\ Zurichbergstr. 14 \\ 8032 Zurich \\ Switzerland \\ egger.@wwi.unizh.ch
}

\author{
Peter Egger \\ Ifo Institute for Economic Research \\ at the University of Munich \\ Poschingerstr. 5 \\ 81679 Munich \\ Germany \\ egger@ifo.de
}

We wish to thank Jeff Bergstrand, Paola Conconi, Jonathan Eaton, Josef Falkinger, Anke Gerber, Holger Görg, Tom Gresik, Rudi Kerschbamer, Jim Markusen, Szylvia Papai, Kali Rath, Armin Schmutzler and Ian Wooton for helpful comments and suggestions. We have benefited from discussions with participants at the Midwest International Economics Fall 2002 Meeting, the SAET 2003 conference, the annual NOEG meeting 2004, the IXth DEGIT conference 2004, the ESEM conference 2004, the ETSG meeting 2004, and at research seminars at the University of Innsbruck, the University of Notre Dame, and the University of Zurich. 


\section{Introduction}

Modern industrial production is characterized by a high degree of vertical fragmentation. Grossman and Helpman (2002a) emphasize that an ever declining scope of activities is undertaken within the boundaries of a single firm (Coase, 1937). Accordingly, Grossman and Helpman (2002b, p. 1) conclude that "We live in an age of outsourcing."

Of course, there is not only evidence for vertical fragmentation per se but also for a rising scope of internationally fragmented production reflected in the growth of intermediate goods trade (Feenstra, 1998). The international economics literature identifies a key role for both national (Burda and Dluhosch, 2002) and international outsourcing (Feenstra and Hanson, 1996, 1999, 2001; Hummels et al., 2001; Kohler, 2004) in the recent wave of globalization. For understanding a firm's international outsourcing decision - i.e., the determinants of intermediate goods trade - transport costs and costs of service links are particularly important (Jones, 2000; Jones and Kierzkowski, 2001; Egger and Egger, 2003). ${ }^{1}$ However, trade models typically ignore national impediments to goods transactions (national transport costs). For Behrens et al. (2003) this as an important handicap and one of the most distinctive features when trade theory is compared to location theory. By referring to insights of Ohlin (1968), they emphasize that "changes in the transportability of commodities (...) between and within countries affect the location of economic activities, (...) the geography of demand and, therefore, the pattern of trade" (ibid., p. 2). ${ }^{2}$ The importance of national transport costs is also emphasized by Anderson and van Wincoop (2004, p. 19) who remark that the "purchase of both foreign and domestic goods need to go through the local distribution system before reaching the final

\footnotetext{
${ }^{1}$ There is broad consensus that, despite technological improvements in recent years, transport costs are still an important characteristic of (national and international) commodity transactions. Based on empirical results, Rietveld and Vickerman (2004, p. 229) argue that "although in terms of money and time, the performance of transport has improved enormously, many economic activities have not become footloose to the extent as expressed by the notion of 'death of distance'. One of the reasons discussed is the role of transaction costs, some being clearly related with distance."

${ }^{2}$ However, costless intra-regional or intra-national goods trade is as well assumed in many of the recent New Economic Geography (NEG) models. As Head and Mayer (2004, p. 10) indicate that "[t]he standard practice in NEG models is to assume free trade within regions" and, at least in empirical applications, regions are often associated with countries.
} 
user", so that sheer geographical distance is associated with unavoidable local transport costs. Accordingly, a rigorous analysis of the role of national and international transport costs in a world with technologically feasible outsourcing should be of particular relevance. Such an analysis requires a model that accounts for the spatial dimension of countries.

Recently, a few studies have accounted for both the geographical dimension and the population size of countries in models of trade with spatial competition à la Hotelling (Shachmurove and Spiegel, 1995; Tharakan, 2001; and Tharakan and Thisse, 2002). Such models allow to investigate the impact of national transport costs on the pattern and volume of trade between adjacent economies. However, the existing studies have focused on final goods trade only.

The contribution of this paper is to introduce fragmentation and outsourcing into a linear model à la Hotelling. This allows us to identify a trade-off of being large and to investigate its impact on the final goods trade pattern and the welfare effects of trade liberalization in a world with two asymmetrically sized economies. This trade-off is driven by the following two effects.

On the one hand, a larger population size leads to a higher degree of vertical specialization and, under autarky, to more intensive national outsourcing. This is a labor division effect, which was first mentioned in Adam Smith's "Wealth of Nations". It implies lower variable production costs in the case of outsourcing and, thus, an advantage of a (population-wise) large economy. ${ }^{3}$ On the other hand, empirical evidence shows that "on average firms facing larger markets are larger" (Kumar et al., 1999, p. 1). Hence, if a population-rich economy is also geographically large ${ }^{4}$, we can on average expect large geographical distances between producers and consumers of final output under autarky. This gives rise to a transport-cost related disadvantage of a (geographically) large economy.

\footnotetext{
${ }^{3} \mathrm{~A}$ positive correlation between the size of population and the possible division of the labor force is also mentioned in Marx' "Das Kapital" (German edition of 1980, vol. 1, chapter 12, p. 373): "Wie für die Teilung der Arbeit innerhalb der Manufaktur eine gewisse Anzahl gleichzeitig angewandter Arbeiter die materielle Voraussetzung bildet, so für die Teilung der Arbeit innerhalb der Gesellschaft die Größe der Bevölkerung und ihre Dichtigkeit, ...”.

${ }^{4}$ For instance, there is a strong positive correlation between geographical area and population size among the EU15 members as well as among the OECD economies.
} 
To analyze this trade-off, we proceed in the following way. In a first step, we set up a partial equilibrium model à la Hotelling with one final goods producer located at the center of a linear economy and compare the autarky equilibrium under integrated production with the autarky equilibrium under (national) outsourcing. In a second step, the free trade equilibrium between two differently sized countries is analyzed. This gives insights in the importance of the aforementioned trade-off of being large for the pattern of trade and the welfare effects of trade liberalization. Moreover, the analysis points to the role of outsourcing for understanding why differently sized economies can simultaneously gain from trade liberalization. In contrast to previous models of final goods trade only, our framework gives rise to gains from trade that render all involved economies better off. This can be important to understand, why economies are willing to participate in free trade agreements like the EU or NAFTA.

Regarding the impact of trade liberalization, we distinguish between short-run (for given entry/exit and location decisions of firms) and long-run effects. This facilitates the exposition and allows us to disentangle pure competition effects from location and entry/exit effects. With respect to the modes of final goods production prevailing in the free trade equilibrium, we consider a number of different scenarios, including the empirically relevant case of national outsourcing in large and international outsourcing in small economies. Indeed, 1995 data of the EU15 economies lend support to the model implications. Namely, (i) national outsourcing of these countries is positively associated with population size with a correlation coefficient of 0.54 ; (ii) the measure of international outsourcing is negatively correlated with population size as reflected by a coefficient of -0.61 (both coefficients are significant at 5\%).

The analysis also contributes to the discussion on market thickness effects of international openness. Similar to McLaren (2000), we can show that falling trade barriers impact on the structure of industrial production, i.e., on whether firms produce integrated or outsource manufacture of inputs. However, our results make clear that this may lead to devastating effects of trade liberalization, regarding the degree of vertical fragmentation in the production of final output. This is a new insight which is in contrast to McLaren's 
"law" of increasing outsourcing and should be of particular relevance for the empirical analysis of the effects of trade liberalization.

The paper is organized in the following way. Sections 2 and 3 present the basic framework of outsourcing in a spatial model à la Hotelling and characterize the autarky equilibrium. Section 4 analyzes trade liberalization between two asymmetrically sized economies and investigates the price-setting behavior and the final goods trade pattern as a function of national transport costs. The focus lies on a short-run perspective for given entry/exit and location decisions of firms. The (short-run) welfare effects of trade liberalization are addressed in Section 5. Section 6 presents two extensions, namely Nash bargaining on input prices (in contrast to an unilateral price choice of the input producer in Sections 3-5) and long-run effects of trade liberalization. Section 7 concludes with a summary of the most important results.

\section{Basic model set up}

Consider a linear model à la Hotelling with one final goods producer located at the center of a country of length $l$, i.e., at $l / 2$. In the following, we use the notion "country $l$ " for such an economy. The location of the final goods producer is fixed. ${ }^{5}$ Population in country $l$ is uniformly distributed along the line $[0, l]$ with one consumer located at each address $b \in[0, l]$. Hence, $l$ refers to both the geographical size of the country and the mass of its population, i.e., the number of consumers. ${ }^{6}$ Each consumer buys at most one unit of the consumption good. "Disutility" from a larger distance of consumers to the final goods producer is represented by quadratic transportation costs. ${ }^{7}$ The marginal willingness to

\footnotetext{
${ }^{5}$ Set-up costs of final goods producers are not explicitly considered for the purpose of notational simplicity. Hence, profits of final goods suppliers refer to operative profits or the producer surplus.

${ }^{6}$ For the main mechanisms and results of our paper, this assumption is not criticial. The findings hold, as long as there is a positive correlation between the geographical size and population size of economies. See Footnote 4 for the empirical stylized facts.

${ }^{7}$ The assumption of quadratic transport costs is not important for the autarky situation. However, this assumption will be crucial for the existence of a Nash-equilibrium in prices under free trade. See the discussion in Footnote 18. There is an extensive literature on the existence of price equilibria in spatial models (see among others d'Aspremont et al., 1979; Anderson, 1987; and Osborne and Pitchik, 1986).
} 
pay for the consumption good depends on the location of a consumer $(b)$ and is given by $A-(b-l / 2)^{2}$, where $l / 2$ is the position of the final goods producer.

The contribution of this study is to allow for two different production technologies in a spatial model of trade. First, as in Shachmurove and Spiegel (1995) and Tharakan and Thisse (2002), there is an integrated production mode, where the whole production process takes place in-house. Second, the final goods producer may fragment the production process and engage in outsourcing by purchasing intermediate inputs from an external supplier at arm's length.

We assume that integrated production (index $i$ ) exhibits constant marginal $\operatorname{costs} c_{i}$, with $A>c_{i}>0$. In the case of outsourcing, the down-stream final goods producer (index d) uses one unit of a component, purchased from an up-stream input supplier (index $u$ ), to manufacture one unit of final output. The input price (net of transport costs) is given by $\rho$. An input producer has to invest fixed costs in the amount of $f$ to set up a production plant. If the input producer does not stay at $l / 2$, there are quadratic transport costs for shipping the component to the final goods producer. Transport costs per unit of the intermediate good are given by $t\left(l / 2-x_{u}\right)^{2}$, where $x_{u} \in[0, l]$ is the location of the input supplier and $l / 2$ the location of the final goods producer. Intermediate inputs and final output are two different types of goods so that the transportation technologies for shipping intermediate and final output may also be different. This is reflected by parameter $t \gtreqless 1$. In the absence of any additional production costs in the down-stream process, $\rho^{d}:=$ $\rho+t\left(l / 2-x_{u}\right)^{2}$ are (transport-cost-including) variable production costs of the downstream final goods producer in the case of outsourcing. The technology of (outsourced) input production exhibits constant marginal production costs $c_{u}$. We assume $c_{u}<c_{i}$. If $\left.c_{i}\right\rangle$ $c_{u}+t\left(l / 2-x_{u}\right)^{2}$, there are gains from fragmenting production (outsourcing). In the following, we use the notion "cost advantage of fragmentation and outsourcing" to refer to these gains which are related to the division of labor. ${ }^{8}$ If there is no input producer Hamoudi and Moral (2003) investigate the existence under concave and convex transport costs. For the
purpose of simplicity, we stick to the textbook case of quadratic transport costs.
${ }^{8}$ Grossman and Helpman (2002a, pp. 90-91) remark the following: " The possibility that production
may be more costly for an integrated firm reflects the fact that its activities are not so highly specialized 
who supplies the required fragment, the final goods producer does not have access to outsourcing and is therefore tied to the integrated production mode.

\section{Autarky equilibrium}

There is a sequence of five decisions that determines the autarky equilibrium: (i) Input producers decide upon entry and location. (ii) After entry, input producers set a price $\rho$ vis-à-vis the final goods producer (a monopolist in the final goods market). ${ }^{9}$ (iii) Based on that price, the transport costs for input transactions and marginal production costs $c_{i}$, the final goods producer chooses between in-house supply of the input (integrated production) and purchases from outside the firm (outsourcing). (iv) The final goods producer finishes the product and sets the mill price for the final good. ${ }^{10}$ (v) Consumers make their purchases. See Figure 1 for a summary of these decisions.

\section{$>$ Figure $1<$}

The autarky equilibrium can be derived through backward induction.

Stage (v) - Consumption: A consumer located at address $b$ has positive demand if $A>p(b):=p+(b-l / 2)^{2}$, where $p$ is the final good's mill price. Hence, aggregate final goods demand is given by ${ }^{11}$

$$
D=\left\{\begin{array}{ccc}
l & \text { if } & p \in\left[0, A-l^{2} / 4\right] \\
2 \sqrt{A-p} & \text { if } & p \in\left(A-l^{2} / 4, A\right] \\
0 & \text { if } & p>A
\end{array} .\right.
$$

and that the bureaucratic cost of managing a larger operation may be higher."

${ }^{9}$ In an extension, we investigate Nash bargaining as an alternative input-price-determination process.

See Subsection 6.1.

${ }^{10}$ We use the term "mill price" in the context of final goods transactions but not in the context of component purchases since we will allow for (spatial) price discrimination of input producers under free trade. See Tharakan (2001) for a similar use of the term.

${ }^{11}$ Remember that each consumer buys at most one unit of the consumption good. 


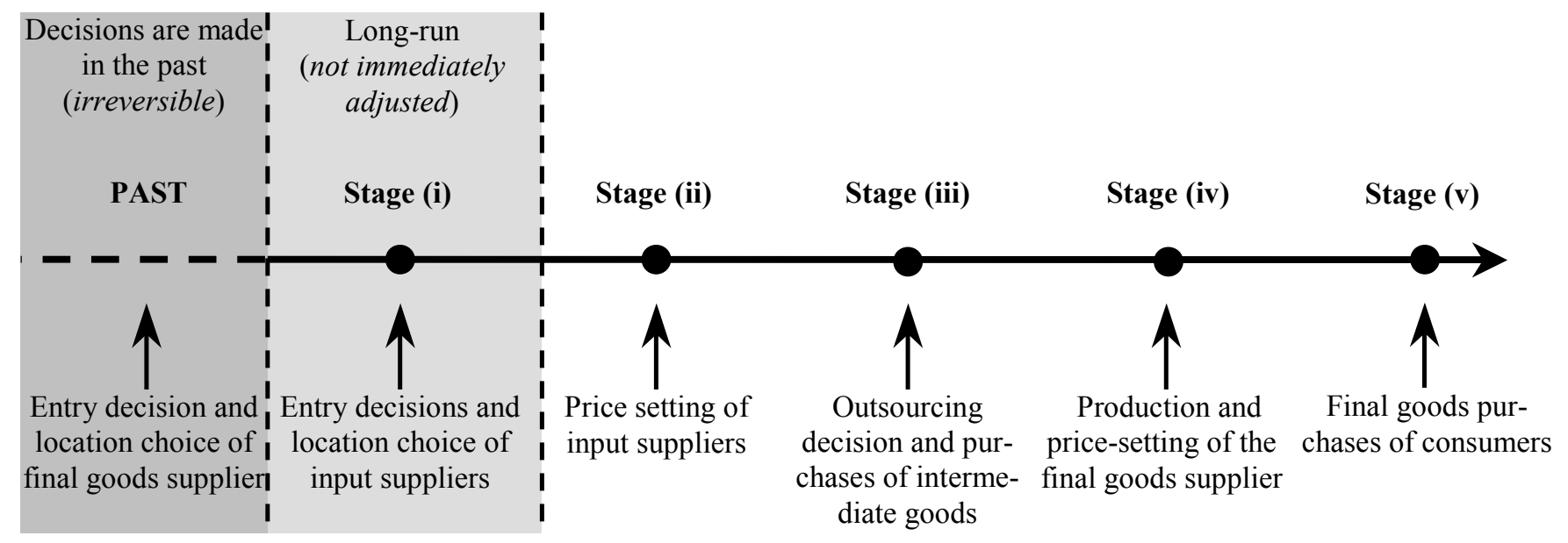

Figure 1. The sequence of decisions 
Stage (iv) - Price setting of the final goods producer: The final goods producer sets the profit-maximizing mill price in view of (1). Profits under integrated production and profits under outsourcing must be distinguished.

First, if the single final goods producer located at the center of market $l$ produces the input in-house (index $i$ ), profits are given by

$$
\pi\left(p_{i}\right)=\left\{\begin{array}{ccc}
2\left(p_{i}-c_{i}\right) \sqrt{A-p_{i}} & \text { if } & p_{i} \in\left(A-l^{2} / 4, A\right] \\
\left(p_{i}-c_{i}\right) l & \text { if } & p_{i} \in\left[0, A-l^{2} / 4\right]
\end{array}\right.
$$

according to (1). ${ }^{12}$ By maximizing profits, the final goods producer sets

$$
p_{i}=\left\{\begin{array}{ccc}
\frac{2 A+c_{i}}{3} & \text { if } & A<c_{i}+3 l^{2} / 4 \\
A-l^{2} / 4 & \text { if } & A \geq c_{i}+3 l^{2} / 4
\end{array} .\right.
$$

Second, under outsourcing the final goods producer's profits are given by

$$
\pi\left(p_{d}\right)=\left\{\begin{array}{ccc}
2\left(p_{d}-\rho^{d}\right) \sqrt{A-p_{d}} & \text { if } & p_{d} \in\left(A-l^{2} / 4, A\right] \\
\left(p_{d}-\rho^{d}\right) l & \text { if } & p_{d} \in\left[0, A-l^{2} / 4\right]
\end{array},\right.
$$

where $\rho^{d}=\rho+t\left(l / 2-x_{u}\right)^{2}$ is the transport-cost-including input price paid by the final goods producer to use the component at location $l / 2$. Maximizing profits (4) gives

$$
p_{d}=\left\{\begin{array}{ccc}
\frac{2 A+\rho^{d}}{3} & \text { if } & A<\rho^{d}+3 l^{2} / 4 \\
A-l^{2} / 4 & \text { if } & A \geq \rho^{d}+3 l^{2} / 4
\end{array} .\right.
$$

Stage (iii) - Outsourcing decision: Substituting (3) and (5) in (2) and (4), respectively, gives

$$
\pi_{i}^{*}=\left\{\begin{array}{ccc}
4\left(\frac{A-c_{i}}{3}\right)^{3 / 2} & \text { if } & A<c_{i}+3 l^{2} / 4 \\
\left(A-l^{2} / 4-c_{i}\right) l & \text { if } & A \geq c_{i}+3 l^{2} / 4
\end{array}\right.
$$

and

$$
\pi_{d}^{*}=\left\{\begin{array}{ccc}
4\left(\frac{A-\rho^{d}}{3}\right)^{3 / 2} & \text { if } & A<\rho^{d}+3 l^{2} / 4 \\
\left(A-l^{2} / 4-\rho^{d}\right) l & \text { if } & A \geq \rho^{d}+3 l^{2} / 4
\end{array} .\right.
$$

\footnotetext{
${ }^{12}$ Of course, $\pi\left(p_{i}\right)=0$ if $p_{i}>A$, according to (1).
} 
Hence, if there is a specialized input producer active in country $l$, the final goods producer opts for outsourcing, if $c_{i} \geq \rho^{d}=\rho+t\left(l / 2-x_{u}\right)^{2}$, and chooses integrated production, if $c_{i}<\rho^{d}=\rho+t\left(l / 2-x_{u}\right)^{2}$.

From now on, the analysis is restricted to a parameter domain that guarantees full coverage under autarky so that all consumers buy one unit of the consumption good, irrespective of whether outsourcing or integrated production is chosen by the final goods producer. A sufficient condition for such a parameter domain is given by Assumption 1 .

Assumption $1 A>c_{i}+3 l^{2} / 4$.

Consider integrated production first. $A>c_{i}+3 l^{2} / 4$ implies $p_{i}=A-l^{2} / 4$ (see (3)). Second, note that outsourcing is chosen if and only if $\rho^{d} \leq c_{i}$. Thus, in the case of outsourcing $A>c_{i}+3 l^{2} / 4$ implies $A>\rho^{d}+3 l^{2} / 4$ and, therefore, $p_{d}=A-l^{2} / 4$ (see (5)). In sum, under Assumption $1, p_{i}=p_{d}=A-l^{2} / 4$ and $D=l$, according to (1), (3) and (5).

Stage (ii) - Price setting of input producers: Let $\mathbf{Z}_{+}^{0}$ be the set of integers equal to or larger than zero and let $n_{u} \in \mathbf{Z}_{+}^{0}$ be the number of identical input producers entering market $l$ at stage (i). Then, according to the analysis of stage (ii) and Assumption 1, operative profits of input producer $j$ are given by

$$
\chi_{j}\left(\rho_{j}\right)=\left\{\begin{array}{ccc}
\left(\rho_{j}-c_{u}\right) l_{j} & \text { if } & \rho_{j} \leq c_{i}-t\left(l / 2-x_{u}^{j}\right)^{2} \\
0 & \text { if } & \rho_{j}>c_{i}-t\left(l / 2-x_{u}^{j}\right)^{2}
\end{array},\right.
$$

if $j$ has entered and located at address $x_{u}^{j}$ in stage (i). $l_{j}, j \in\left[1, n_{u}\right]$, denotes the amount of sales of input producer $j$, if $n_{u} \geq 1 .^{13}$ Furthermore, if $n_{u}=1$ and there is a cost advantage of fragmentation and outsourcing as compared to integrated production, i.e., if $c_{u} \leq c_{i}-t\left(l / 2-x_{u}\right)^{2}$, the profit-maximizing input price is ${ }^{14} \rho=c_{i}-t\left(l / 2-x_{u}\right)^{2}$ and the achieved operative profit (or producer surplus) is

$$
\chi^{*}=\left[c_{i}-t\left(l / 2-x_{u}\right)^{2}-c_{u}\right] l .
$$

\footnotetext{
${ }^{13}$ If all input producers locate at the same address (and $n_{u} \geq 1$ ), $l_{j}=l / n_{u}$, since all firms are identical.

${ }^{14}$ Note that $\rho=c_{i}-t\left(l / 2-x_{u}\right)^{2}$ implies $\rho^{d}=c_{i}$.
} 
In contrast, price competition at the input market leads to $\rho=c_{u}$ and $\chi^{*}=0$, if $n_{u} \geq 2$ and input producers decide for the same (profit-maximizing) address at stage (i).

Stage (i) - Entry decision and location choice of input producers: Input producers enter and settle down at the profit-maximizing location $x_{u}=l / 2$, if there is a prospect of positive profits, i.e., if $\chi^{*} \geq f$. In view of $(9)$, there is no entry of input suppliers and integrated final goods production prevails, if $l<\left(c_{i}-c_{u}\right) / f$. In contrast, if $l \geq\left(c_{i}-c_{u}\right) / f$, then price competition at stage (ii) implies that only one input producer will enter and stay in the market at location $x_{u}=l / 2$. If $n_{u} \geq 2$, then input producers will always earn negative profits $\chi^{*}-f<0$ and, therefore, prefer to exit the market, see stage (ii). Thus, $n_{u} \geq 2$ is not consistent with the concept of a long-run autarky equilibrium.

The main findings of the backward induction are summarized in Proposition 1.

Proposition 1 Under Assumption 1 the following holds in the autarky equilibrium:

(a) If $l \geq\left(c_{i}-c_{u}\right) / f$, a single input producer enters and settles at the center of market $l$, i.e., at location $x_{u}=l / 2$. Then, $\rho=c_{i}$ and $p_{d}=A-l^{2} / 4$ are profit-maximizing input and final goods prices, respectively, and operative profits are given by $\chi^{*}=\left(c_{i}-c_{u}\right) l$ and $\pi_{d}^{*}=\left(A-l^{2} / 4-c_{i}\right) l$.

(b) If $l<\left(c_{i}-c_{u}\right) / f$, no input producer will enter so that integrated production prevails. In this case, $p_{i}=A-l^{2} / 4$ is the relevant final goods price and $\pi_{i}^{*}=\left(A-l^{2} / 4-c_{i}\right) l$ is the corresponding profit.

Proof. Proposition 1 follows from the backward induction above.

If an input producer enters at stage (i), she sets an input price that renders the final goods producer indifferent between integrated production and outsourcing so that the input producer gets the whole specialization rent. This is a direct consequence of the price-determination process in the input market. (For the impact of bargaining on the autarky equilibrium, see Section 6.1.)

In the following analysis, we consider two asymmetrically sized economies: a small one of size $s=1$ and a large one of size $L>1$. The two economies may differ with respect 
to the existence of an input producer (see Proposition 1). In all other respects the two countries are identical and Assumption 1 holds for both countries so that there is full coverage under autarky.

\section{$>$ Figure $2<$}

Figure 2 illustrates the autarky equilibrium in the two differently sized economies. According to Proposition 1, the final goods producer in country $s$ sets a higher mill price than its counterpart in country $L: p_{s}^{a}=A-1 / 4>p_{L}^{a}=A-L^{2} / 4$, where $a$ refers to autarky. Serving the whole market implies higher transport costs and, thus, for a given willingness to pay $A$, a lower mill price in country $L$. This result depends on Assumption 1 but it is independent of which production techniques are used in the two economies.

Regarding the mode of final goods production in the two asymmetrically sized countries, we can distinguish three cases, according to Proposition 1: (1) one with no specialized input producer active in countries $s$ and $L$, i.e., only the integrated production mode is available for the two final goods producers; (2) one with a single input producer active in the large economy, but no input producer located in country $s$; and (3) one with two input producers, one located in either economy. In the next section, we analyze prices and the trade pattern in the free trade equilibrium. Thereby, we focus on short-run effects and assume that location and entry/exit decisions of final and intermediate goods producers are given (and are the same as under autarky). Furthermore, due to the restriction of space and motivated by empirical stylized facts on national and international outsourcing presented in the introductory section, we focus on case (2) and assume that there is a single input producer active in the large economy, but no input producer active in country s. (Formally, we consider a parameter domain $s=1<\left(c_{i}-c_{u}\right) / f \leq L$.) A discussion of cases (1) and (3) is relegated to Subsection 6.2, where the long-run effects associated with entry/exit and location decisions of input producers under free trade are considered. 


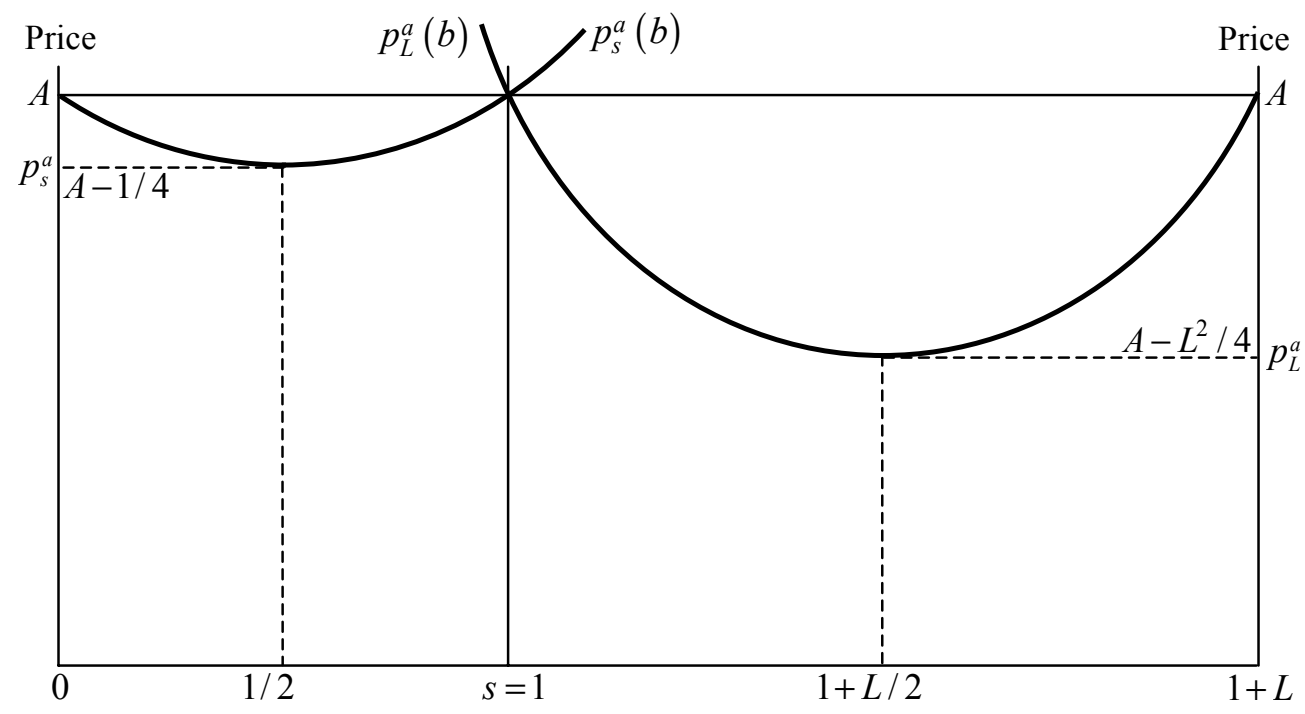

Figure 2. Autarky equilibrium in two asymmetrically sized economies 


\section{Free trade equilibrium}

To analyze the impact of trade liberalization, we follow the common approach and assume that tariffs on final goods as well as intermediate goods trade between countries $s$ and $L$ fall from infinity to zero. Free trade means that consumers have the choice to purchase the final good from either seller (i.e., from the one located at the center of country $s$ or the one located at the center of country $L$ ), but must bear the corresponding quadratic transport costs. This implies that under free trade some consumers may purchase the final good abroad. Hence, there is cross-country competition of final goods producers instead of the monopoly under autarky. This may but does not necessarily result in lower final goods prices as has been shown by Tharakan and Thisse (2002). In addition, final goods producers may purchase the component from abroad, if an input producer is active there.

For the moment, we focus on short-run effects and do not investigate location and entry/exit decisions of firms. These decisions are exogenously given. In terms of Figure 1, we analyze the stage (ii)-(v) equilibrium for given (autarky) decisions at stage (i). Long-run effects associated with a stage (i)-(v) equilibrium are addressed in Section 6. As motivated above, we focus on a scenario with a single input producer being active in the large economy. Again, we solve the equilibrium through backward induction.

Stage (v) - Consumption: For given final goods prices $p_{s}, p_{L}$ in $s$ and $L$, respectively, the marginal consumer is located in interval $[0,1+L]$ and its address is determined by

$$
x_{m}\left(p_{s}, p_{L}\right)=\left\{\begin{array}{ccc}
0 & \text { if } & p_{L}-p_{s}<-\frac{(L+3)(L+1)}{4} \\
\frac{p_{L}-p_{s}}{L+1}+\frac{L+3}{4} & \text { if } & \left(p_{L}-p_{s}\right) \in\left[-\frac{(L+3)(L+1)}{4}, \frac{(3 L+1)(L+1)}{4}\right] . \\
L+1 & \text { if } & p_{L}-p_{s}>\frac{(3 L+1)(L+1)}{4}
\end{array}\right.
$$

Define

$$
\begin{aligned}
v:=\frac{1}{2}+\sqrt{A-p_{s}}, \quad w: & =\frac{1}{2}-\sqrt{A-p_{s}} \\
y:=1+\frac{L}{2}+\sqrt{A-p_{L}}, & z:=1+\frac{L}{2}-\sqrt{A-p_{L}} .
\end{aligned}
$$


Then, for given prices $p_{s}, p_{L}$,

$$
\begin{aligned}
& D_{s}=\left[\min \left(v, x_{m}\right)-\max (0, w)\right] \\
& D_{L}=\left[\min (L+1, y)-\max \left(z, x_{m}\right)\right]
\end{aligned}
$$

represent the demand for final output produced in country $s$ and country $L$, respectively.

Stage (iv) - Price setting of the two final goods producers: Let $\rho^{k}, k=s, L$, be the price net of transport costs of an input sold to the final goods producer in country $k$. Moreover, in the case of outsourcing let $\rho^{k, d}$ be the transport-cost-including input price paid by the final goods producer located at the center of country $k=s, L$. Given the autarky location of the input producer in country $L, \rho^{L, d}=\rho^{L}$ and $\rho^{s, d}=\rho^{s}+t(L+1)^{2} / 4$. $(L+1) / 2$ is the distance between the final goods producer in $s$ and the input supplier in $L$ (see Figure 2). We introduce a further variable $c^{k} \in\left\{c_{i}, \rho^{k, d}\right\}, k=s, L$, to account for the two production modes. Thereby, $c^{k}=c_{i}$ holds, if the final goods producer in country $k$ produces integratedly, whereas $c^{k}=\rho^{k, d}$ are marginal production costs of the down-stream process, if the final goods producer outsources component production.

According to (13) and (14), free trade profits of the final goods producers in $s$ and $L$ are given by

$$
\pi_{s}=\left(p_{s}-c^{s}\right) D_{s}
$$

and

$$
\pi_{L}=\left(p_{L}-c^{L}\right) D_{L},
$$

respectively.

For the case of integrated production in both economies, Tharakan and Thisse (2002) identify four parameter domains, which determine the set of possible price equilibria. It is beyond the scope of this paper to provide a rigorous analysis of all possible parameter domains. Therefore, we introduce a further (empirically plausible) assumption, namely that trade liberalization has a pro-competitive effect and leads to full coverage under free trade. A sufficient condition for such an outcome is given by Assumption 2. ${ }^{15}$

\footnotetext{
${ }^{15}$ Note that Assumption 2 implies Assumption 1 for both countries. Hence, there is full coverage under autarky, if there is full coverage under free trade.
} 
Assumption $2 A>c_{i}+\frac{15 L^{2}+12 L}{12}$.

Lemma 1 Under Assumption 2, for all ${ }^{16} c^{k} \leq c_{i}, k=s, L$, the following holds in a free trade equilibrium. (1) Demand for final goods produced at the two locations is given by $D_{s}=x_{m}\left(p_{s}, p_{L}\right)$ and $D_{L}=L+1-x_{m}\left(p_{s}, p_{L}\right)$, respectively. (2) There is full coverage in the free trade equilibrium with each consumer buying one unit of final output, i.e., $D_{s}+D_{L}=L+1$. (3) Profits of the two final goods producers are given by

$$
\pi_{s}=\left(p_{s}-c^{s}\right) x_{m}\left(p_{s}, p_{L}\right)
$$

and

$$
\pi_{L}=\left(p_{L}-c^{L}\right)\left(L+1-x_{m}\left(p_{s}, p_{L}\right)\right)
$$

respectively.

\section{Proof. See Appendix A.}

To obtain a unique equilibrium in prices, we impose a restriction on the price-setting behavior of firms, namely $p_{k} \geq c^{k}, k=s, L .{ }^{17}$ Then, maximizing profits (17) and (18) gives, according to (10),

$$
p_{s}^{*}=\left\{\begin{array}{ccc}
c^{s} & \text { if } & c^{L} \leq c^{s}-\gamma_{1} \\
\frac{c^{L}+2 c^{s}}{3}+\frac{(5 L+7)(L+1)}{12} & \text { if } & \left(c^{L}-c^{s}\right) \in\left(-\gamma_{1}, \gamma_{2}\right) \\
c^{L}-\frac{(3 L+1)(L+1)}{4} & \text { if } & c^{L} \geq c^{s}+\gamma_{2}
\end{array}\right.
$$

and

$$
p_{L}^{*}=\left\{\begin{array}{clc}
c^{s}-\frac{(L+3)(L+1)}{4} & \text { if } & c^{L} \leq c^{s}-\gamma_{1} \\
\frac{2 c^{L}+c^{s}}{3}+\frac{(7 L+5)(L+1)}{12} & \text { if } & \left(c^{L}-c^{s}\right) \in\left(-\gamma_{1}, \gamma_{2}\right) \\
c^{L} & \text { if } & c^{L} \geq c^{s}+\gamma_{2}
\end{array}\right.
$$

\footnotetext{
${ }^{16}$ As shown in stage (iii), $c^{k}>c_{i}$ is not consistent with an equilibrium.

${ }^{17}$ It is shown in the proof of Appendix A that some $p_{k}<c^{k}$ may be consistent with an equilibrium, if there are zero sales of the final goods producer located in country $k$. Such price equilibria are ruled out by the proposed assumption on the price-setting behavior of firms. For a logically similar problem in a different context, see Ludema and Wooton (2000).
} 
where $\gamma_{1}:=(5 L+7)(L+1) / 4$ and $\gamma_{2}:=(7 L+5)(L+1) / 4 .{ }^{18}$ Note that $p_{s}^{*}<p_{s}^{a}=$ $A-1 / 4$ and $p_{L}^{*}<p_{L}^{a}=A-L^{2} / 4$ are a direct consequence of $c^{s} \leq c_{i}, c^{L} \leq c_{i}$ and Assumption 2. Substituting (19) and (20) in (10) gives the equilibrium location of the marginal consumer

$$
x_{m}^{*}\left(c^{s}, c^{L}\right)=\left\{\begin{array}{ccc}
0 & \text { if } & c^{L} \leq c^{s}-\gamma_{1} \\
\frac{c^{L}-c^{s}}{3(L+1)}+\frac{5 L+7}{12} & \text { if } & \left(c^{L}-c^{s}\right) \in\left(-\gamma_{1}, \gamma_{2}\right) \\
L+1 & \text { if } & c^{L} \geq c^{s}+\gamma_{2}
\end{array} .\right.
$$

Stage (iii) - Outsourcing decision: The final goods producer in country $k=s, L$ chooses outsourcing, if $\rho^{k, d} \leq c_{i}$. Otherwise, production is integrated.

Stage (ii) - Price setting of the input producer: Two cases must be distinguished with respect to the size of transport costs for input transactions: (a) $t>$ $4\left(c_{i}-c_{u}\right) /(L+1)^{2}$ and (b) $t \leq 4\left(c_{i}-c_{u}\right) /(L+1)^{2}$. We investigate Case (a) first.

\subsection{Technical exclusion of international outsourcing: Case (a)}

Let us first show that $t>4\left(c_{i}-c_{u}\right) /(L+1)^{2}$ is not consistent with international outsourcing in the free trade equilibrium. For this, note that $t>4\left(c_{i}-c_{u}\right) /(L+1)^{2}$ can be reformulated as $c_{u}>c_{i}-t(L+1)^{2} / 4$. Hence, negative profits are obtained for sales to the final goods producer in country $s$, if a price $\rho^{s} \leq c_{i}-t(L+1)^{2} / 4<c_{u}$ is chosen by the input supplier. According to $(21), D_{L}=L+1-x_{m}\left(c^{s}, c^{L}\right)$ is non-decreasing in $c^{s}$. Therefore, the results of stage (iii) for the outsourcing decision of the two final goods producers imply that international outsourcing is not consistent with a profit-maximizing price of the input producer, if $t>4\left(c_{i}-c_{u}\right) /(L+1)^{2}$. The input producer chooses

\footnotetext{
18 The existence of a price equilbrium (19) and (20) critically depends on the assumption of quadratic transport costs. d'Aspremont et al. (1979) show that a minimum distance between the locations of the two final goods producers is essential for the existence of a Nash equilibrium in prices under linear transport costs. However, as shown in Tharakan (2001) this "minimum distance condition" is not satisified by locations $1 / 2$ and $1+L / 2$ of the two final goods producers (and country sizes $L>s=1$ ). Therefore, a price equilibrium under linear transport costs is not consistent with our assumptions regarding the locations of the two final goods producers (at least if marginal production costs of the two final goods producers are identical, i.e., if $c^{s}=c^{L}$; see our discussion below).
} 
$\rho^{s}>c_{i}-t(L+1)^{2} / 4$ and final goods production in country $s$ remains integrated under free trade. In this case, we speak of technical exclusion of international outsourcing (since the transportation technology does not allow for international outsourcing).

If $\rho^{L}>c_{i}$, operative profits of the input producer are zero. If $\rho^{L} \in\left(c_{u}, c_{i}\right]$, operative profits are positive and given by ${ }^{19}$

$$
\chi=\left\{\begin{array}{ccc}
\left(\rho^{L}-c_{u}\right)\left[(L+1)-\left(\frac{\rho^{L}-c_{i}}{3(L+1)}+\frac{5 L+7}{12}\right)\right] & \text { if } & \rho^{L} \in\left[c_{i}-\gamma_{1}, c_{i}\right] \\
\left(\rho^{L}-c_{u}\right)[L+1] & \text { if } & \rho^{L}<c_{i}-\gamma_{1}
\end{array},\right.
$$

with $\gamma_{1}=(5 L+7)(L+1) / 4$. The input producer faces the following trade-off by setting the optimal price. On the one hand, a lower price reduces revenues for a given volume of sales. But on the other hand, a lower price increases demand for intermediate goods, since it makes the final goods producer in country $L$ more competitive and reduces her transport-cost-related size disadvantage for serving consumers located near the common border, see (21).$^{20}$ In other words, the final goods producer of country $L$ can participate in the cost advantage of fragmentation and outsourcing, if the input producer sets a price lower than $c_{i}$. According to (22), profit maximization of the input producer gives

$$
\rho^{L *}=\left\{\begin{array}{ccc}
c_{i}-\frac{(5 L+7)(L+1)}{4} & \text { if } & c_{i}>\overline{c_{i}} \\
\frac{c_{i}+c_{u}}{2}+\frac{(7 L+5)(L+1)}{8} & \text { if } & c_{i} \in\left[\underline{c_{i}}, \overline{c_{i}}\right] \\
c_{i} & \text { if } & c_{i} \in\left(c_{u}, \underline{c_{i}}\right)
\end{array},\right.
$$

with $\underline{c_{i}}:=c_{u}+(7 L+5)(L+1) / 4$ and $\overline{c_{i}}:=c_{u}+(17 L+19)(L+1) / 4$. Note that $\rho^{L *}$ depends on final goods transport costs and the size of the two economies but it does not depend on parameter $t$, since international outsourcing does not occur in equilibrium. It is an immediate consequence of $(23)$ that $\rho^{L}<c_{i}-(5 L+7)(L+1) / 4$ cannot be an optimal price choice. The reason is that at an input price $\rho^{L}=c_{i}-(5 L+7)(L+1) / 4$ the marginal consumer is located at $x_{m}=0$, according to $(21)$, and the whole integrated market $(L+1)$ is served by the final goods producer of country $L$, i.e., $D_{L}=L+1$.

\footnotetext{
${ }^{19}$ Substituting $c_{i}=c^{s}$ and $\rho^{L}\left(\leq c_{i}\right)=c^{L}$ in $(21)$ gives $D_{L}=L+1-x_{m}\left(c_{i}, \rho^{L}\right)>0$. This is used in (22).

${ }^{20}$ We speak of a transport-cost-related size disadvantage of the large economy, since country $L$ imports the final good, i.e., $x_{m} \in(1, L+1)$, at $c^{s}=c^{L}$.
} 
Thus, a further price reduction cannot be an optimal strategy for the input producer, since it leaves the volume of sales unaffected. At the other extreme, it may as well be the case that, even for a marginal price reduction below $c_{i}$, gains from a higher sales volume cannot offset losses from lower per unit revenues. Then, setting the component price at its autarky level $\rho^{L}=c_{i}$ is the optimal price choice for the input producer. In all other cases, $\rho^{L}=\left(c_{i}+c_{u}\right) / 2+(7 L+5)(L+1) / 8$ is the profit-maximizing input price.

The transport-cost-related size disadvantage of the large economy implies that the final goods mill price under free trade is higher in country $L$ than in country $s$, if $\rho^{L *}=c_{i}$, according to (19) and (20). Things are different, if trade liberalization leads to a reduction of the input price, i.e., to $\rho^{L *}<c_{i}$. In this case, the final goods producer in country $L$ can participate in the cost advantage of fragmentation and outsourcing. This increases its competitiveness and results in a lower final goods price $p_{L}^{*}$ (see $(20)$ ). Final goods prices are strategic complements. Accordingly, the final goods producer in the small country will also reduce its price, if $\rho^{L}$ (and - according to (20) - in turn also $p_{L}^{*}$ ) declines. However, it is obvious from a comparison of (19) and (20) that the reduction of $p_{L}^{*}$ is more pronounced than the reduction of $p_{s}^{*}$. This implies that the marginal consumer shifts to the left, if $\rho^{L}$ declines (see (21)).

The possible impact of outsourcing on final goods prices under free trade is drawn in Figure 3 , where $p_{L}^{1}(b)$ and $p_{s}^{1}(b)$ refer to input prices $\rho^{L}=c_{i}$, whereas $p_{L}^{2}(b)$ and $p_{s}^{2}(b)$ refer to input prices $\rho^{L}<c_{i}$. Noteworthy, the downward shift of the dotted price-location schedule from $p_{L}^{1}(b)$ to $p_{L}^{2}(b)$ is more pronounced than the downward shift from $p_{s}^{1}(b)$ to $p_{s}^{2}(b)$, if the input producer sets $\rho^{L}<c_{i}$. (See the discussion above.)

\section{$>$ Figure $3<$}

Substituting $c_{i}=c^{s}$ and, according to (23), $\rho^{L}=c^{L}$ in (21) gives the equilibrium location of the marginal consumer

$$
x_{m}^{*}=\left\{\begin{array}{ccc}
0 & \text { if } & c_{i}>\overline{c_{i}} \\
\frac{c_{u}-c_{i}}{6(L+1)}+\frac{17 L+19}{24} & \text { if } & c_{i} \in\left[\underline{c_{i}}, \overline{c_{i}}\right] . \\
\frac{5 L+7}{12} & \text { if } & c_{i} \in\left(c_{u}, \underline{c_{i}}\right)
\end{array} .\right.
$$




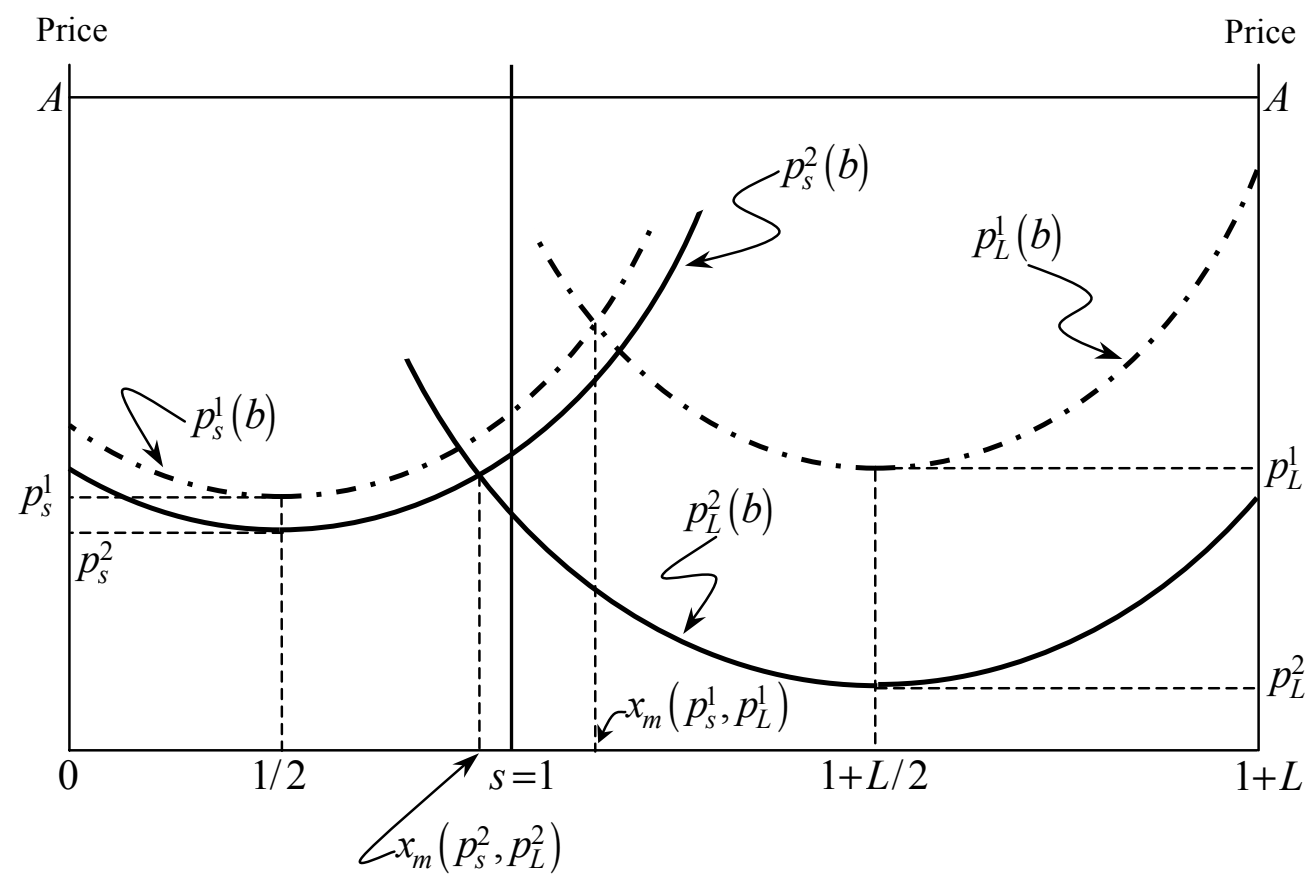

Figure 3. Free final goods trade with $\rho^{L^{*}}=c_{i}$ and $\rho^{L^{*}}<c_{i}$ 
Whether the marginal consumer is located in the large or in the small economy depends on the relative strength of two opposing forces (i.e., the following trade-off of being large), namely the transport-cost-related size disadvantage and the outsourcing-related production cost advantage of country $L$. The latter is induced by lower marginal production $\operatorname{costs} c_{u}<c_{i}{ }^{21}$ The outsourcing-related production cost advantage of the large country is dominant, if $c_{i}-c_{u}>(17 L-5)(L+1) / 4$. According to $(24)$, the marginal consumer is located in the small economy and country $L$ exports the consumption good. This case is drawn in Figure 3. In contrast, the marginal consumer is located in $L$ and the small country exports the consumption good, if $c_{i}-c_{u}<(17 L-5)(L+1) / 4$. In this case, the transport-cost-related size disadvantage dominates the outsourcing-related production cost advantage of country $L$. In the borderline case of $c_{i}-c_{u}=(17 L-5)(L+1) / 4$, the marginal consumer is located at the common border and there is no trade in the free trade equilibrium (see (24)).

\subsection{International outsourcing from $s$ to $L$ : Case (b)}

If transport costs for input transactions are sufficiently low, i.e., if $t \leq 4\left(c_{i}-c_{u}\right) /(L+1)^{2}$, and if $\rho^{s} \in\left(c_{u}, c_{i}-t(L+1)^{2} / 4\right]$, the input producer earns non-negative operative profits for sales to the final goods producer in country $s$. Moreover, note that the whole integrated market $(L+1)$ is served at input prices $\rho^{s}=\rho^{L}=c_{i}-t(L+1)^{2} / 4$. And, according to (21), lower prices $\rho^{k}$ vis-à-vis the final goods producer in country $k$ imply lower (at least not higher) intermediate goods sales to country $k^{\prime}$ for a given $\rho^{k^{\prime}}$, with $k^{\prime} \neq k$. Hence, $\rho^{s}<c_{i}-t(L+1)^{2} / 4$ and/or $\rho^{L}<c_{i}-t(L+1)^{2} / 4$ are not consistent with profit maximization of the input producer. In view of stage (iii), this implies that the profit-maximizing input price vis-à-vis the final goods producer in country $s$ is given by $\rho^{s *}=c_{i}-t(L+1)^{2} / 4$, leading to $\rho^{s, d}=c_{i}$. This renders the final goods producer in

\footnotetext{
${ }^{21}$ As mentioned in Section 2, the notion of "cost advantage of fragmentation and outsourcing" refers to cheaper production under outsourcing than under integrated production. This is a prerequisite for the "outsourcing-related production cost advantage of country $L$ " (over country $s$ ), which arises due to the existence of a local input producer and the related national outsourcing opportunities in country $L$.
} 
country $s$ indifferent between integrated production and international outsourcing. Profits of the input producer are given by ${ }^{22}$

$$
\chi=\left\{\begin{array}{ccc}
\left(\rho^{L}-c_{u}\right)(L+1)-\left(\rho^{L}-\rho^{s}\right)\left[\frac{\rho^{L}-c_{i}}{3(L+1)}+\frac{5 L+7}{12}\right] & \text { if } & \rho^{L} \in\left[c_{i}-\gamma_{1}, c_{i}\right] \\
\left(\rho^{L}-c_{u}\right)[L+1] & \text { if } & \rho^{L}<c_{i}-\gamma_{1}
\end{array},\right.
$$

with $\gamma_{1}=(5 L+7)(L+1) / 4$. Using $\rho^{s *}=c_{i}-t(L+1)^{2} / 4$ in the profit-maximization problem of country $L$ 's input producer gives the optimal price vis-à-vis the final goods producer in country $L$

$$
\rho^{L *}=\left\{\begin{array}{ccc}
c_{i}-\frac{(5 L+7)(L+1)}{4} & \text { if } & t>\frac{17 L+19}{L+1} \\
c_{i}-t \frac{(L+1)^{2}}{8}+\frac{(7 L+5)(L+1)}{8} & \text { if } & t \in\left[\frac{7 L+5}{L+1}, \frac{17 L+19}{L+1}\right] . \\
c_{i} & \text { if } & t<\frac{7 L+5}{L+1}
\end{array} .\right.
$$

Thus, by maximizing profits, the input producer applies price discrimination and sets $\rho^{L *}>\rho^{s *}($ as long as $t>0)$.

While transport costs for input transactions are zero in the case of national outsourcing, international outsourcing induces transport costs in the amount of $t(L+1)^{2} / 4$ for shipping one unit of the input from the upstream producer located at the center of country $L$ to the downstream producer located at the center of country $s$. Hence, there is again an outsourcing-related production cost advantage of country $L$ over country $s .^{23}$ Moreover, the final goods producer in country $s$ cannot participate in the cost advantage of fragmentation and outsourcing over integrated production, given the optimal price choice $\rho^{s *}=c_{i}-t(L+1)^{2} / 4$, which implies $\rho^{s, d}=c_{i} \cdot{ }^{24}$ Things are different in the large economy, where the final goods producer can participate in the cost advantage of fragmentation and outsourcing, if the input producer sets $\rho^{L}<c_{i}$. The optimal price choice $\rho^{L *}$ itself depends on transport costs for input transactions and, therefore, on parameter $t$. The lower

\footnotetext{
${ }^{22}$ Substituting $c_{i}=\rho^{s, d}=c^{s}$ and $\rho^{L}=c^{L} \leq c_{i}$ in $(21)$ gives $D_{s}=x_{m}\left(c_{i}, \rho^{L}\right) \geq 0$ and $D_{L}=$ $L+1-x_{m}\left(c_{i}, \rho^{L}\right)>0$. This is used in $(25)$.

${ }^{23}$ Final goods production costs include all costs that are necessary to manufacture final output. Hence, they also include transport costs for intermediate goods transactions in the case of international outsourcing.

${ }^{24}$ For the difference in the use of the two notions "outsourcing-related production cost advantage of country $L "$ and "cost advantage of fragmentation and outsourcing", see Footnote 21.
} 
parameter $t$, the higher is $\rho^{L *}$, according to (26). If $t$ is high enough, there are profits to gain from setting $\rho^{L}<c_{i}$. However, if $t$ is low, setting $\rho^{L}<c_{i}$ reduces profits. The reason is that losses for given sales dominate gains arising from higher sales to the local final goods supplier. These additional sales come at the costs of lower exports to country $s$ (which are associated with positive operative profits, if $\left.t<4\left(c_{i}-c_{u}\right) /(L+1)^{2}\right) .{ }^{25}$

Substituting $c_{i}=\rho^{s, d}=c^{s}$ and, according to (26), $\rho^{L *}=c^{L}$ in (21) gives the equilibrium location of the marginal consumer

$$
x_{m}^{*}=\left\{\begin{array}{ccc}
0 & \text { if } & t>\frac{17 L+19}{L+1} \\
\frac{17 L+19}{24}-t \frac{L+1}{24} & \text { if } & t \in\left[\frac{7 L+5}{L+1}, \frac{17 L+19}{L+1}\right] . \\
\frac{5 L+7}{12} & \text { if } & t<\frac{7 L+5}{L+1}
\end{array}\right.
$$

The location of the marginal consumer again depends on two opposing effects, namely the transport-cost-related size disadvantage and the outsourcing-related production cost advantage of country $L$. Taking this trade-off of being large into account gives the following result. If transport costs are sufficiently high, i.e., if $t>(17 L-5) /(L+1)$ and $t \leq 4\left(c_{i}-c_{u}\right) /(L+1)^{2}$, the input producer sets price $\rho^{L}$ low enough, such that the marginal consumer is located in country $s$ and country $L$ exports the consumption good. In this case, the outsourcing-related production cost advantage (in the form of access to intermediate goods without transport costs) dominates the transport-cost-related size disadvantage of the large economy. The opposite holds true, if $t<(17 L-5) /(L+1)$. In this case, the marginal consumer is located in country $L$ and country $s$ exports the consumption good. In the borderline case of $t=(17 L-5) /(L+1)$, the marginal consumer is located at the common border and trade of final goods does not occur. However, there are intermediate goods exports of the large economy, i.e., international outsourcing of the final goods producer in country $s$.

The main findings for the two different scenarios analyzed in Subsections 4.1 and 4.2 are summarized in Proposition 2.

\footnotetext{
${ }^{25}$ Due to $(7 L+5) /(L+1)>1$, it follows from $(26)$ that $\rho^{L *}=c_{i}$ for all $t \leq 1$. Hence, $\rho^{L *}<c_{i}$ requires that transportation of intermediate goods induces higher costs than transportation of final output.
} 
Proposition 2 Under Assumption 2, if there is a single input producer located in country $L$, the following holds. In the free trade equilibrium there is international outsourcing of the final goods producer in country s, if transport costs for input transactions are not too high, i.e., if $t \leq 4\left(c_{i}-c_{u}\right) /(L+1)^{2}$. In contrast, $t>4\left(c_{i}-c_{u}\right) /(L+1)^{2}$ implies technical exclusion of international outsourcing and integrated production in country s. In both cases, country L exports the consumption good, if the outsourcing-related production cost advantage dominates the transport-cost-related size disadvantage of the large economy. Otherwise, country s exports the consumption good.

Proof. Proposition 2 follows from the analysis above.

\section{$5 \quad$ Welfare effects of trade liberalization}

In Section 4 we have investigated how trade liberalization affects the price-setting behavior of input and final goods producers. This has shed some light on the trade pattern between two asymmetrically sized economies. The results of the above analysis are now used to determine the welfare effects of trade liberalization. In particular, we investigate in which way trade patterns and outsourcing opportunities are related to the welfare effects of trade liberalization. The sum of consumer surplus and profits serves as our welfare measure. Again, we focus on short-run effects and relegate the discussion of entry/exit and optimal location decisions to Subsection 6.2.

It is an immediate consequence of Assumption 2 and the induced pro-competitive effect of trade liberalization on final goods prices that consumers in both economies benefit from a tariff reduction. ${ }^{26}$ Moreover, it can be shown that welfare in the final goods exporting country always increases. The pro-competitive effect of falling tariffs leads to a price reduction in both economies and, therefore, to lower profits from local sales. However, in the final goods exporting country these profit losses are fully compensated by consumer surplus gains. In addition to this welfare-neutral redistribution effect, there are profit

\footnotetext{
${ }^{26}$ This is a mere price effect, since Assumptions 1 and 2 guarantee full coverage under autarky and free trade.
} 
gains from final goods exports, leading to a positive welfare effect in the final goods exporting country. This outcome is independent of the production techniques used in the two economies.

Which one of the two economies exports the final good depends on the respective parameter values. In Section 4, it has been shown that the outsourcing-related production cost advantage of a large, population-rich economy may outweigh its transport-cost-related size disadvantage so that it becomes the final goods exporter and, therefore, benefits from trade liberalization. However, it is not only relevant which one of the two economies exports/imports the final good to determine winners and losers of trade liberalization. If there is an outsourcing-related production cost advantage of the large economy, then both countries may gain from tariff reductions. On the one hand, if $\rho^{L}$ is chosen low enough and country $L$ exports the final output, consumer surplus gains may dominate profit losses in the small economy. Hence, welfare in country $s$ may increase, even if it imports the consumption good. On the other hand, in the case of international outsourcing the large economy benefits from intermediate goods exports so that welfare in the large country may increase, even if it imports the consumption good.

Table 1 summarizes the (short-run) welfare effects of trade liberalization. The existence of international outsourcing depends on three factors: (a) the cost advantage of fragmentation and outsourcing $c_{i}-c_{u}$, (b) the transport cost parameter $t$, and (c) the distance between the location of the final goods producer in country $s$ and the location of the input producer in country $L$, i.e., $(L+1) / 2$. The higher the cost advantage $c_{i}-c_{u}$ and the lower the parameter $t$ and the distance $(L+1) / 2$ (i.e., the lower $L$ ), the more likely is international outsourcing in the free trade equilibrium. For the pattern of final goods trade, also relative country size $L-1$ (or, more precisely, $17 L-5$ ) turns out to be important (see Table 1). According to the considerations above, international outsourcing prevails in equilibrium and country $L$ exports final output, if the cost advantage of fragmentation and outsourcing $\left(c_{i}-c_{u}\right)$ is high and the difference in country sizes $(L-1)$ is not too large. A higher degree of market integration at the intermediate goods level, i.e., a lower $t$, makes final goods exports of country $L$ less likely. Things are different if the 
cost advantage of fragmentation and outsourcing $\left(c_{i}-c_{u}\right)$ is moderate and transport costs for input transactions (depending on the parameter $t$ and the distance $(L+1) / 2$ ) are high. In this case, international outsourcing is technologically excluded. Again, country $L$ exports final output, if it is not too large and, therefore, its transport-cost-related size disadvantage is not too high. The larger country $L$ relative to country $s$ (in geographical terms), the more likely it is that country $s$ exports the final good. ${ }^{27}$

TABLE 1 . Welfare effects of trade liberalization if only in country $L$ there is intermediate input production

\begin{tabular}{|c|c|c|c|c|}
\hline & $\begin{array}{l}\text { Final goods ex- } \\
\text { porting country }\end{array}$ & $\begin{array}{l}\text { Welfare effects } \\
\text { in country } s\end{array}$ & $\begin{array}{l}\text { Welfare effects } \\
\text { in country } L\end{array}$ & $\begin{array}{c}\text { World welfare } \\
\text { effects }\end{array}$ \\
\hline \multicolumn{5}{|c|}{ Technical exclusion of international outsourcing, i.e., $t>4 \frac{c_{i}-c_{u}}{(L+1)^{2}}$} \\
\hline (i) $c_{i}-c_{u}<\frac{(17 L-5)(L+1)}{4}$ & country $s$ & + & - & $a m b$. \\
\hline (ii) $c_{i}-c_{u}=\frac{(17 L-5)(L+1)}{4}$ & no final goods trade & 0 & 0 & 0 \\
\hline (iii) $c_{i}-c_{u}>\frac{(17 L-5)(L+1)}{4}$ & country $L$ & $a m b$. & + & + \\
\hline \multicolumn{5}{|c|}{ International outsourcing from $s$ to $L$, i.e., $t \leq 4 \frac{c_{i}-c_{u}}{(L+1)^{2}}$} \\
\hline (iv) $t<\frac{17 L-5}{L+1}$ & country $s$ & + & $a m b$. & $a m b$. \\
\hline (v) $t=\frac{17 L-5}{L+1}$ & no final goods trade & 0 & $+/ 0$ & $+/ 0$ \\
\hline (vi) $t>\frac{17 L-5}{L+1}$ & country $L$ & $a m b$. & + & + \\
\hline
\end{tabular}

Notes: In this matrix, "+", “-", and "0" mean that trade liberalization has a positive, negative or no effect on the respective welfare levels. "amb." indicates that the impact is ambiguous.

Table 1 shows that the small and the large country can simultaneously benefit from declining trade barriers (scenarios (iii), (iv) and (vi)). This is an important result, since it makes trade liberalization an attractive policy in both countries without requiring cross-country redistribution measures. The existence of gains from trade in all (involved)

\footnotetext{
${ }^{27} \mathrm{~A}$ formal proof of the results in Table 1 is relegated to Appendix B.
} 
economies is a result that is well-known from the traditional trade literature. However, the positive effects of free trade are less clear in new trade theory models with imperfect competition in goods markets. Wong (1995) gives an excellent overview on the gains from trade for economies under imperfections. As far as spatial models are concerned, Tharakan and Thisse (2002) investigate the impact of the geographical size of countries on the distribution of welfare gains. In their model of final goods trade only, they come up with the result that "large countries, unlike small ones, should be less inclined towards free trade" (p. 399), since their welfare decreases in response to trade liberalization. In this case, the welfare effects are determined by the transport-cost-related size disadvantage of the large economy. (Compare the welfare effects under integrated production in both economies derived in Subsection 6.2. $)^{28}$

Our analysis also points to the possibility that trade liberalization leads to a decline in overall world welfare, if exports of the small economy (partially) substitute local sales in the large country, which are manufactured under a superior production mode and/or without any transport costs for intermediate goods transactions (scenarios (i) and (iv) in Table 1). Thus, trade liberalization is not always beneficial but may exert immiserizing world welfare effects. To put it differently, overall producer surplus losses may dominate overall consumer surplus gains.

\section{Extensions and further discussion}

The analysis in Sections 4 and 5 gave insights into the role of country size for the trade pattern and the welfare effects of trade liberalization. Moreover, it was shown how the geographical size and the population size interact in determining the pattern of final goods trade. In particular, the existence of a trade-off of being large in terms of a transportcost-related size disadvantage and an outsourcing-related production cost advantage was

\footnotetext{
${ }^{28}$ Tharakan (2001) shows in a Hotelling model that both the geographical sizes and the population densities of countries are important determinants of the welfare effects of trade liberalization. Behrens et al. (2003) discuss the welfare effects of reductions in international trade barriers and national/regional transport costs.
} 
pointed out. However, the results were derived under two restictive assumptions. On the one hand, we assumed that input prices were unilaterally set by the input producer. Given the existing literature on outsourcing in macroeconomic settings, one may be interested in the robustness of our results with respect to this assumption. Therefore, we investigate bargaining on input prices between the intermediate and final goods producers in Subsection 6.1. On the other hand, in Sections 4 and 5 we focused on short-run effects, neglecting any adjustments in the entry/exit or location decisions of firms. This assumption is relaxed in Subsection 6.2, where the long-run effects of trade liberalization are at the agenda. The limitation of space does not allow for a rigorous formal discussion of these issues, so that Subsections 6.1 and 6.2 present the main insights in an intuitive way. ${ }^{29}$ Finally, Subsection 6.3 relates the main insights of our long-run considerations to the discussion on international openness and the industrial structure. Moreover, the respective welfare effects of trade liberalization are summarized and considered from a policy perspective.

\subsection{Bargaining on input prices}

The results in Sections 3-5 are derived under the assumption that the input producer can unilaterally set a price vis-à-vis final goods suppliers. This assumption differs from the price determination process usually considered in the outsourcing literature. ${ }^{30}$ The purpose of this subsection is to discuss the robustness of our results by allowing for Nash bargaining on input prices between upstream (input) and downstream (final goods) producers. In all other respects, the analysis in Subsection 6.1 corresponds to the analysis in Sections 3-5. Again, we start with a discussion of the autarky equilibrium.

\footnotetext{
${ }^{29} \mathrm{~A}$ detailed formal analysis is relegated to a supplement, which is available from the authors upon request.

${ }^{30}$ Grossman and Helpman (2002a, 2002b), for example, allow for bargaining between final goods and input producers. In contrast, Helsely and Strange (2004) investigate take-it-or-leave-it offers by final goods suppliers, while McLaren (2000) assumes an auction mechanism.
} 


\section{Autarky equilibrium}

Note first that the analysis in stages (iii)-(v) of the stage (i)-(v) autarky equilibrium is not affected by the aforementioned modification. Therefore, we focus on stages (i) and (ii), when analyzing the impact of Nash bargaining between the input and final goods producer. For simplicity ant to make the following results directly comparable with the ones derived in Section 3-5, we assume that not more than one input producer can enter the market at stage (i). If an input producer has entered market $l$ and located at address $x_{u}^{a}$, the Nash product under autarky is given by ${ }^{31}$

$$
\Omega^{a}=\left\{\pi_{d}^{a}-\pi_{i}^{a}\right\}^{\xi}\left\{\chi^{a}\right\}^{1-\xi}
$$

where $\xi \in(0,1)$ indicates the bargaining power of final goods producers and index $a$ refers to autarky. According to our analysis in Section 3, we can substitute $\pi_{d}^{a}, \pi_{i}^{a}$ and $\chi^{a}$ in (28) to obtain

$$
\Omega^{a}=l\left\{c_{i}-\rho-t\left(l / 2-x_{u}^{a}\right)^{2}\right\}^{\xi}\left\{\rho-c_{u}\right\}^{1-\xi} .
$$

Maximizing (29) with respect to $\rho$, then gives the following equilibrium input price (and, thus, the solution to stage (ii)), if a single producer enters at stage (i)

$$
\rho^{a}=\xi c_{u}+(1-\xi)\left[c_{i}-t\left(l / 2-x_{u}^{a}\right)^{2}\right]
$$

Using (30) in stage (i), we can show that $x_{u}^{a}=l / 2$ is the optimal location of input production under autarky. Moreover,

$$
l \geq \frac{f}{(1-\xi)\left(c_{i}-c_{u}\right)} \equiv \widetilde{f}
$$

gives a necessary and sufficient condition for entry of a single input producer. In sum, Nash bargaining leads to a lower input price $\rho^{a}=\xi c_{u}+(1-\xi) c_{i}$ under autarky and makes entry of an input producer less likely. Final goods prices are not affected.

\footnotetext{
${ }^{31}$ At stage (ii), the outside option of the input producer is $-f$ and her contribution to the Nash product equals $\chi^{a}$.
} 
Free trade equilibrium with $t>4\left(c_{i}-c_{u}\right) /(L+1)^{2}$

Let us focus on a short-run free trade equilibrium with given entry/exit and location decisions of firms and a single input producer active in country $L$. This is consistent with optimal decisions under autarky, if paramter domain $L \geq \widetilde{f}>s=1$ prevails. The solutions to stages (iii)-(v) are identical to those derived in Section 4. The only difference arises with respect to the price determination process in stage (ii). When focussing on parameter domain $t>4\left(c_{i}-c_{u}\right) /(L+1)^{2}$, it is obvious that there is technical exclusion of international outsourcing as shown in Subsection 4.1. Moreover, it is intuitively clear and can formally be shown that the input price vis-à-vis the final goods producer in the large economy is lower (at least not higher) under Nash bargaining than under a unilateral price choice of the input producer as considered in Section 4. Hence, under Nash bargaining on input prices it is more likely that the marginal consumer is resident of the small economy and that country $L$ exports final output in a free trade equilibrium with technical exclusion of international outsourcing. Moreover, welfare effects in the large economy are more likely to be positive, while the impact on welfare effects in the small economy is less clear-cut.

Free trade equilibrium with $t \leq 4\left(c_{i}-c_{u}\right) /(L+1)^{2}$

From Subsection 4.2, we know that the input producer may have an incentive to bargain with both final goods suppliers, if $t \leq 4\left(c_{i}-c_{u}\right) /(L+1)^{2}$. We think of bargaining as a two step process. In step one, firms decide on whether to participate in a Nash bargain or not. Based on these decisions, there is Nash bargaining on input prices in step two. At this stage, it is common knowledge, which firms participate in a Nash bargaining unit. In line with the literature on trade union theory (see, e.g., Layard and Nickell, 1990; Beissinger and Egger, 2004), firms have perfect foresight and, therefore, anticipate the outcome of the other bargaining unit (if one exists). There is no possibility to renegotiate the bargaining outcome. Hence, if bargaining fails, the outside options are realized.

Unfortunately, the complexity of this problem does not allow us to use analytical tools. 
Rather, we must stick to simulation techniques and have to solve numerical examples. Thereby, we use the following parameter values $\xi=0.45, c_{u}=1, c_{i}=35, A=100$, $L \in[2,4.75]$ and $t \in[1,5.75]$ to obtain a contour plot for the possible patterns of final goods trade.

\section{$>$ Figure $4<$}

From Figure 4 it is obvious that both regime $x_{m} \in[0,1)$, with country $L$ exporting the final good, and regime $x_{m} \in(1, L+1)$, with country $L$ importing the final good, are consistent with Nash bargaining on input prices. A higher transport cost parameter $t$ (for a given country size $L$ ) raises the outsourcing-related production cost advantage of the large economy and, therefore, makes final goods exports of country $L$ more likely. This coincides with our findings in Subsection 4.2. To the contrary, a larger country size in geographical terms amplifies the transport-cost-related size disadvantage. As a consequence, a higher $L$ makes final goods exports of country $s$ more likely. However, there is a further effect of country size $L$ and transport cost parameter $t$. For sufficiently high levels of $t$ and $L$, we end up with a parameter domain $t>4\left(c_{i}-c_{u}\right) /(L+1)^{2}$, implying technical exclusion of international outsourcing in the free trade equilibrium. This is, what happens above and to the right of the bold line in (the top right corner of) Figure 4, where the final goods producer in country $L$ has exclusive access to the intermediate goods manufactured by the specialized input producer.

We are not only interested in the pattern of final goods trade but also in the welfare effects of trade liberalization. These effects are illustrated in Figure 5. As long as country size differences and transport costs for input transactions are not too large, trade liberalization should increase welfare in both economies. However, welfare gains are less likely for the large economy if $L$ is high. Welfare gains in the small country are less likely for high levels of transport costs and sufficiently large $L$. Under such a parameter domain, there is not much scope for bargaining on input prices and the consumers in $s$ cannot sufficiently participate in the outsourcing-related production cost advantage of country $L$. Such an outcome is in accordance with the welfare effects presented in Section 5. 


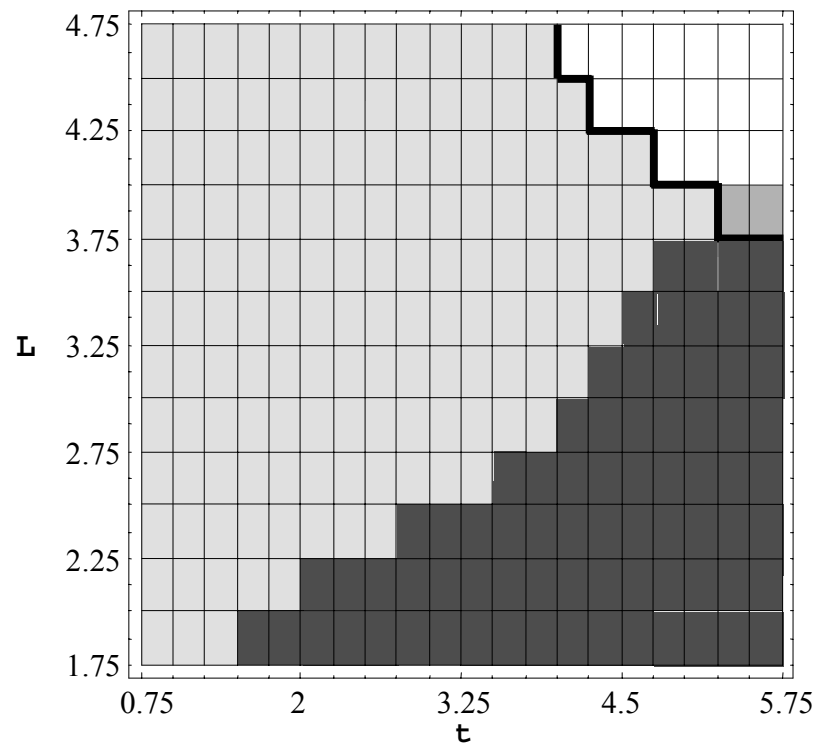

Region 1: $x_{m} \in(0,1)$ and bargaining with both final goods suppliers;

Region 2: $x_{m} \in(0,1)$ and exclusive bargaining with the final goods supplier in $L$;

Region 3: $x_{m} \in(1, L+1)$ and bargaining with both final goods suppliers;

Region 4: $x_{m} \in(1, L+1)$ and exclusive bargaining with the final goods supplier in $L$.

Figure 4. Different bargaining outcomes (Contour plot) 


\section{$>$ Figure $5<$}

Summing up, we can conclude that the main results of Sections 4 and 5 survive, if we allow for bargaining on input prices. In this sense, our focus on input-price-setting by the input producer can be interpreted as a simplifying rather than restrictive assumption.

\subsection{Long-run effects of trade liberalization}

To investigate the long-run effects of trade liberalization, we consider the basic model assumptions and, in particular, assume that the input producer unilaterally sets a price vis-à-vis the final goods suppliers. Due to price competition at the input market, it is intuitive that not more than two input producers can survive in the long-run free trade equilibrium. Hence, we have to account for three regimes with regard to the number of active input producers: (a) no input producer is active; (b) two input producers are active; (c) one input producer remains active.

\section{Scenario (a): A long-run equilibrium with integrated production in both economies}

Using $c^{s}=c_{i}$ and $c^{L}=c_{i}$ in (19), (20) and (21), we find that final goods prices in the long-

run free trade equilibrium are $p_{s, i}^{*}=c_{i}+\frac{(5 L+7)(L+1)}{12}$ and $p_{L, i}^{*}=c_{i}+\frac{(7 L+5)(L+1)}{12}$, if production is integrated in both economies. The marginal consumer is located at $x_{m}^{*}=\frac{5 L+7}{12}$, implying final goods exports of country $s$.

At identical mill prices, the final goods producer in country $L$ faces a transport-costrelated disadvantage vis-à-vis its competitor in $s$ for serving consumers located near the common border. In addition, final goods producers take into account the following two effects of a price reduction. On the one hand, for a given price of the competitor a lower final goods price implies higher final goods sales as the marginal consumer moves away (see (10)). But on the other hand, it results in lower revenues for given output. This negative profit effect is higher for the final goods supplier in country $L$, due to its larger hinterland (given by interval $[1+L / 2, L+1]$ ). Hence, the final goods producer in the 


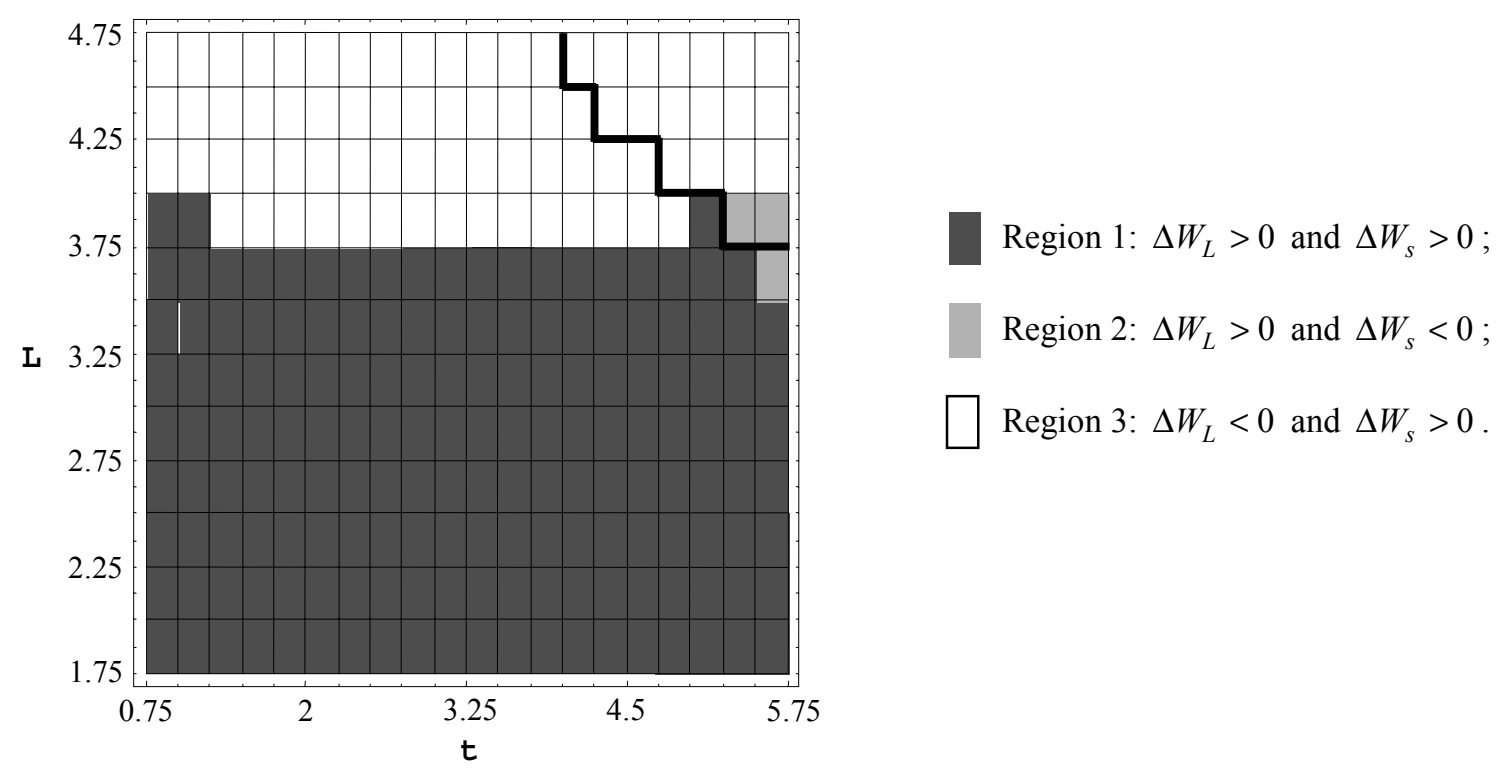

Figure 5. Welfare effects of trade liberalization (Contour plot) 
large country optimally chooses a higher price than its competitor in the small economy. Together with the transport-cost-related disadvantage of country $L$ for serving consumers located close to the common border, this implies that the marginal consumer is resident of the large country (located at address $x_{m}=\frac{5 L+7}{12}<1+L / 2$ ) and the small country exports the final good.

Compared with welfare under autarky, the export-related profit gains lead to a welfare increase of $\Delta W_{s}^{L R}=\int_{1}^{\frac{5 L+7}{12}}\left[p_{s, i}^{*}-c_{i}\right] d b>0$ in the small economy. (Superscript $L R$ always refers to the long-run.) This corresponds to the general observation that trade liberalization is always beneficial for the final goods exporting country. Things are different in the large country, where welfare changes can be written $\mathrm{as}^{32}$

$$
\Delta W_{L}^{L R}=\underbrace{\int_{1}^{\frac{5 L+7}{12}}\left[[b-(1+L / 2)]^{2}-[b-1 / 2]^{2}\right] d b}_{\Delta T}-\int_{1}^{L+1}\left(c_{i}-c_{u}\right) d b+f-\Delta W_{s}^{L R},
$$

with $\Delta T=\frac{5}{288}(L+1)(L-1)^{2}$ representing the transport cost disadvantage of country $L$ for serving consumers located close to the common border. It can be shown that consumer surplus gains are dominated by profit losses so that trade liberalization induces a welfare decline in country $L$, which is given by $\Delta W_{L}=-\frac{5}{96}\left(3 L^{3}+5 L^{2}-3 L-5\right)-\left(c_{i}-c_{u}\right) L+$ $f<0$. Finally, overall world welfare changes are ambiguous. On the one hand, there are positive effects due to a reduction in transport cost expenditures for sales to interval $\left[1, \frac{5 L+7}{12}\right)$, i.e., $\Delta T>0$. On the other hand, there are negative welfare effects, since the superior outsourcing technology in country $L$ is replaced by the integrated production mode. In sum, we find $\Delta W^{L R}=\Delta W_{s}^{L R}+\Delta W_{L}^{L R}=\Delta T-\left(c_{i}-c_{u}\right) L+f \gtreqless 0$ The sign of $\Delta W^{L R}$ depends on the particular parameter constellation and is in general ambiguous.

\section{Scenario (b): A long-run equilibrium with two input producers}

Note first that for any location of input producer $1, x_{u}^{1}$, there are only two candidates for an optimal location choice of input producer 2 , namely $x_{u}^{2}=1 / 2$ and $x_{u}^{2}=1+L / 2$.

${ }^{32} \int_{1}^{L+1}\left(c_{i}-c_{u}\right) d b-f>0$ are profits of the input producer under autarky, which do not have an analogon in the long-run free trade equilibrium if production in both economies is integrated. 
This is an immediate consequence of positive transport costs for input transactions (see our discussion in Section 3). Moreover, if $x_{u}^{1}=1 / 2$, then $x_{u}^{2}=1+L / 2$ is the best choice, while $x_{u}^{2}=1 / 2$ is the best response to $x_{u}^{1}=1+L / 2$. As a consequence, the two input producers are separated to locations $x_{u}^{s}=1 / 2$ and $x_{u}^{L}=1+L / 2$ (the best reply location choices).

Given locations $x_{u}^{s}=1 / 2$ and $x_{u}^{L}=1+L / 2$, we can show that there is competitive exclusion of international outsourcing and both final goods producers make use of national outsourcing opportunities in the long-run free trade equilibrium. Due to a larger hinterland, the input producer in the large country has an incentive to set a higher (at least not a lower) price than the input producer in the small economy. This implies that the transport-cost-related size disadvantage of the large economy is (potentially) reinforced and that the small country exports the consumption good. An outsourcing-related production cost advantage of the large country does not arise.

Welfare effects of trade liberalization are qualitatively equivalent to those identified for the case of integrated production in both economies. Welfare in the small country rises and welfare in the large country declines. Overall world welfare is ambiguously affected by trade liberalization. On the one hand, there is a decline in overall transport cost expenditures, which tends to increase world welfare. On the other hand, there is entrance of a second input producer, which can only survive due to final goods exports of country $s$ to country $L$. This tends to reduce world welfare.

\section{Scenario (c): A long-run equilibrium with one input producer}

If only one input producer is active in the long-run free trade equilibrium (and location decisions are not made strategically to deter competitors from entry), there are two candidates for an optimal location choice. If transport costs for input transactions are high, i.e., if $t$ is large, the profit-maximizing address for input production is given by $x_{u}^{*}=1+L / 2$. As a consequence, input prices and welfare effects coincide with those determined in Sections 4 and 5 for the short-run equilibrium (with given location and entry/exit decisions of input suppliers). In contrast, if parameter $t$ is sufficiently low, 
the optimal location is given by $x_{u}^{*}=(7 L+17) / 24$, with profit-maximizing input prices $\rho^{L}=c_{i}-t(5 L+7)^{2} / 576$ and $\rho^{s}=c_{i}-t(7 L+5)^{2} / 576$ vis-à-vis the final goods producers in countries $L$ and $s$, respectively. In this case, $c^{s}=c^{L}=c_{i}$ and $x_{m}=(5 L+7) / 12$, according to (21), so that the marginal consumer is resident of the large economy.

With regard to the long-run welfare effects of trade liberalization, we focus on parameter domains that make $x_{u}=(7 L+17) / 24$ the profit-maximizing location of input production, if only one input producer is active. Welfare effects for $x_{u}=1+L / 2$ coincide with the respective welfare effects in the short-run, discussed in Section 5. Since country $s$ exports final output (i.e., since $\left.x_{m}=(5 L+7) / 12\right)$, welfare changes in the small economy must be positive. They are given by $\Delta W_{s}^{L R}=\int_{1}^{x_{m}^{L R}}\left[p_{s}^{L R}-c_{i}\right] d b>0$. Moreover, welfare changes in the large economy can be written as

$$
\begin{array}{r}
\Delta W_{L}^{L R}=-\left(x_{m}^{L R}-1\right)\left\{\frac{(3 L+5)(L+1)}{8}+t\left[\left(\frac{7 L+5}{24}\right)^{2}+\frac{7 L+5}{10(L-1)}\left(\frac{5 L+7}{24}\right)^{2}\right]\right\} \\
+\left(c_{i}-c_{u}\right)-t\left(\frac{7 L+5}{24}\right)^{2} \cdot(33)
\end{array}
$$

It is worth noting that $\Delta W_{L}^{L R}$ may be positive or negative, depending on the respective parameter domain. Concerning the change of overall world welfare, we obtain

$$
\begin{array}{r}
\Delta W^{L R}=\left(x_{m}^{L R}-1\right)\left\{\frac{(L-1)(L+1)}{24}-t\left[\left(\frac{7 L+5}{24}\right)^{2}\right.\right. \\
\left.\left.+\frac{7 L+5}{5(L-1)}\left(\frac{5 L+7}{24}\right)^{2}\right]\right\} \\
+\left(c_{i}-c_{u}\right)-t\left(\frac{7 L+5}{24}\right)^{2} .
\end{array}
$$

which may also be positive or negative.

\subsection{Further discussion}

In this subsection, we compare our results to insights from the literature dealing with the relationship between international openness and the structure of industrial production. A further purpose is to summarize the long-run welfare effects and to discuss them from a policy perspective. 


\section{Trade liberalization and the structure of industrial production}

As rigorously analyzed in Subsection 4.2, trade liberalization may lead to international outsourcing and, thus, to a change in the small economy's mode of final goods production. In the long-run, when entry/exit and location decisions of input producers are endogenous, there may be entry of a further input producer and national outsourcing in both economies. This result coincides with findings by McLaren (2000) who emphasizes that market thickness effects lead to leaner and less integrated firms, when countries lower their trade barriers. However, as made clear by scenario (a) in Subsection 6.1, competition effects may also make exit of the single input producer attractive, so that integrated production in both economies is the outcome under free trade. This is associated with a negative efficiency effect, because the superior outsourcing technology is replaced. The possibility of such a devastating outcome is a new insight and of particular relevance, when measuring the gains of trade empirically.

\section{Long-run welfare effects: A policy perspective}

In view of the analysis above, there is no clear-cut prediction regarding the long-run welfare effects of trade liberalization. If competition leads to an exit of the single input producer and, therefore, implies integrated production in both economies or if a second input producer enters the integrated market in the long-run, the outsourcing-related production cost advantage of the large economy vanishes. Then, country $s$ exports final output. As a consequence, there are welfare gains in the small and welfare losses in the large economy. Overall world welfare is ambiguously affected. However, if a single input producer remains active in the long-run, its autarky location at $x_{u}=1+L / 2$ may remain optimal so that trade pattern and welfare effects coincide with those determined in Sections 4 and 5 for the short-run equilibrium. In contrast, if the transport cost parameter $t$ is low, it is optimal for a single input producer to move closer to the common border and to locate at address $x_{u}=(7 L+5) / 24$. In this case, the degree of international outsourcing and the magnitude of intermediate goods exports to the small economy increase, 
raising profits of country L's input producer. This may give rise to welfare gains of the large economy, even though the small country exports final output (and, thus, faces a welfare improvement).

The long-run effects of trade liberalization point to the relevance of outsourcing opportunities for welfare gains. Only if there is an outsourcing-related production cost advantage in the large economy, both small and large countries can simultaneously gain from trade liberalization without measures of cross-country redistribution. (Compare the welfare effects under scenarios (a) and (b) with those under scenario (c).) As a consequence, one may hypothesize that improved outsourcing opportunities from the 70s onwards play a key role in explaining the wave of trade liberalization observed in that period. And with regard to the economic success of the EU, the theoretical insights in this subsection suggest that better outsourcing opportunities for European firms can explain the pace of the European integration process.

\section{Concluding remarks}

This paper contributes to the discussion of international trade in a spatial set-up, where countries are areas rather than points. By emphasizing the role of outsourcing opportunities, our analysis is capable to identify a trade-off of being large. On the one hand, firms in geographically large economies face a transport-cost-related disadvantage with respect to serving consumers close to borders. On the other hand, if geographically large economies are population-rich, they face an outsourcing-related production cost advantage due to a higher degree of vertical specialization and the dividion of labor.

With regard to the trade pattern between two asymmetrically sized economies, our analysis reveals the main fundamentals, determining which country exports and which country imports final output. Based on these insights, the presented model allows us to discuss the role of national transport costs for the (short-run and long-run) welfare effects of trade liberalization. In particular, the results point to the relevance of outsourcing opportunities and provide an economic reasoning for the willingness of countries to lower 
their tariffs and to enter a free trade agreement with partner countries that differ in size and economic capacity. Moreover, our framework provides novel insights into the impact of trade liberalization on the structure of industrial production. In this respect, the potential negative effects of trade liberalization on the intensity of fragmentation and outsourcing are of particular relevance and should be investigated in future research.

\section{Appendix}

\section{Appendix A: Proof of Lemma 1}

Consider $A>c_{i}+\left(15 L^{2}+12 L\right) / 12$, according to Assumption 2, and use $c^{s} \leq c_{i}, c^{L} \leq c_{i}$. The proof is organized in two steps:

\section{Step (i): Price-setting and interior solutions}

Consider first price-setting in country $s$. Use

$$
\pi_{s}=\left\{\begin{array}{ccc}
\left(p_{s}-c^{s}\right) x_{m}\left(p_{s}, p_{L}\right) & \text { if } & p_{s} \leq p_{s}^{a} \\
\left(p_{s}-c^{s}\right)\left[\min \left(v, x_{m}\right)-w\right] & \text { if } & p_{s}>p_{s}^{a}
\end{array}\right.
$$

according to $(10),(11),(13)$ and (15). Moreover, define $D_{s}^{1}:=\left(p_{L}-p_{s}\right) /(L+1)+$ $(L+3) / 4\left(=x_{m}\right), D_{s}^{2}:=\left(p_{L}-p_{s}\right) /(L+1)+(L+1) / 4+\sqrt{A-p_{s}}\left(=x_{m}-w\right)$ and $D_{s}^{3}:=v-w=2 \sqrt{A-p_{s}}$, according to (10) and (11). Substituting $D_{s}^{1}, D_{s}^{2}$ and $D_{s}^{3}$ for $D_{s}$ in (15) gives

$$
\begin{aligned}
\phi_{s}^{1} & :=\left(p_{s}-c^{s}\right)\left(\frac{p_{L}-p_{s}}{L+1}+\frac{L+3}{4}\right), \\
\phi_{s}^{2} & :=\left(p_{s}-c^{s}\right)\left(\frac{p_{L}-p_{s}}{L+1}+\frac{L+1}{4}+\sqrt{A-p_{s}}\right), \\
\phi_{s}^{3} & :=\left(p_{s}-c^{s}\right) 2 \sqrt{A-p_{s}},
\end{aligned}
$$

respectively. Profits $\pi_{s}$ are continuous in $p_{s}$ and can be written as a composite of $\phi_{s}^{1}, \phi_{s}^{2}$ and $\phi_{s}^{3}$, according to (35)-(38). (Hence, the properties of $\phi_{s}^{j}$ translate into the properties 
of $\pi_{s}$.) The first derivatives of (36)-(38) with respect to $p_{s}$ are given by

$$
\begin{aligned}
\frac{\partial \phi_{s}^{1}}{\partial p_{s}} & =\frac{p_{L}-p_{s}}{L+1}+\frac{L+3}{4}-\frac{\left(p_{s}-c^{s}\right)}{L+1} \\
\frac{\partial \phi_{s}^{2}}{\partial p_{s}} & =\frac{p_{L}-p_{s}}{L+1}+\frac{L+1}{4}+\sqrt{A-p_{s}}-\frac{\left(p_{s}-c^{s}\right)}{L+1}\left(1+\frac{1}{2} \frac{L+1}{\sqrt{A-p_{s}}}\right), \\
\frac{\partial \phi_{s}^{3}}{\partial p_{s}} & =2 \sqrt{A-p_{s}}-\frac{p_{s}-c^{s}}{\sqrt{A-p_{s}}} .
\end{aligned}
$$

Evaluating (39)-(41) at autarky prices $p_{s}^{a}=A-1 / 4, p_{L}^{a}=A-L^{2} / 4$ gives

$$
\begin{aligned}
& \left.\frac{\partial \phi_{s}^{1}}{\partial p_{s}}\right|_{\left(p_{s}^{a}, p_{L}^{a}\right)}=\frac{c^{s}+L+5 / 4-A}{L+1} \\
& \left.\frac{\partial \phi_{s}^{2}}{\partial p_{s}}\right|_{\left(p_{s}^{a}, p_{L}^{a}\right)}=\frac{L+1-(L+2)\left(A-c^{s}-1 / 4\right)}{L+1} \\
& \left.\frac{\partial \phi_{s}^{3}}{\partial p_{s}}\right|_{\left(p_{s}^{a}, p_{L}^{a}\right)}=2 c^{s}+3 / 2-2 A .
\end{aligned}
$$

It can be shown that, for any $c^{s} \leq c_{i}, A>c_{i}+\left(15 L^{2}+12 L\right) / 12$ is sufficient for $\partial \phi_{s}^{j} /\left.\partial p_{s}\right|_{\left(p_{s}^{a}, p_{L}^{a}\right)}<0, j=1,2,3$. Due to $\partial^{2} \phi_{s}^{j} / \partial\left(p_{s}^{j}\right)^{2}<0, \partial^{2} \phi_{s}^{j} / \partial p_{s} \partial p_{L} \geq 0$ and the fact that $\pi_{s}$ is a continuous function in $p_{s}$ (see (35)), it follows that $p_{L} \leq p_{L}^{a}$ and $D_{s}>0$ are only consistent with a free trade equilibrium, if $p_{s}<p_{s}^{a}$. (Existence of such an equilibrium will be discussed below.)

Now consider price-setting in country $L$. Use

$$
\pi_{L}=\left\{\begin{array}{ccc}
\left(p_{L}-c^{L}\right)\left[L+1-x_{m}\left(p_{s}, p_{L}\right)\right] & \text { if } & p_{L} \leq p_{L}^{a} \\
\left(p_{L}-c^{L}\right)\left[y-\max \left(z, x_{m}\right)\right] & \text { if } & p_{L}>p_{L}^{a}
\end{array}\right.
$$

according to $(10),(12),(14)$ and (16). Moreover, define $D_{L}^{1}:=(3 L+1) / 4-\left(p_{L}-p_{s}\right) /(L+1)$ $\left(=L+1-x_{m}\right), D_{L}^{2}:=(L+1) / 4-\left(p_{L}-p_{s}\right) /(L+1)+\sqrt{A-p_{L}}\left(=y-x_{m}\right)$ and $D_{L}^{3}:=y-z=2 \sqrt{A-p_{L}}$, according to (10) and (12). Substituting $D_{L}^{1}, D_{L}^{2}$ and $D_{L}^{3}$ for $D_{L}$ in (16) gives

$$
\begin{aligned}
\phi_{L}^{1} & :=\left(p_{L}-c^{L}\right)\left(\frac{3 L+1}{4}-\frac{p_{L}-p_{s}}{L+1}\right) \\
\phi_{L}^{2} & :=\left(p_{L}-c^{L}\right)\left(\frac{L+1}{4}-\frac{p_{L}-p_{s}}{L+1}+\sqrt{A-p_{L}}\right), \\
\phi_{L}^{3} & :=\left(p_{L}-c^{L}\right) 2 \sqrt{A-p_{L}}
\end{aligned}
$$


respectively. Profits $\pi_{L}$ are continuous in $p_{L}$ and can be written as a composite of $\phi_{L}^{1}, \phi_{L}^{2}$ and $\phi_{L}^{3}$, according to (45)-(48). (Hence, he properties of $\phi_{L}^{j}$ translate into the properties of $\pi_{L}$.) The first derivatives of (46)-(48) with respect to $p_{L}$ are given by

$$
\begin{aligned}
\frac{\partial \phi_{L}^{1}}{\partial p_{L}} & =\frac{p_{s}-p_{L}}{L+1}+\frac{3 L+1}{4}-\frac{p_{L}-c^{L}}{L+1} \\
\frac{\partial \phi_{L}^{2}}{\partial p_{L}} & =\frac{p_{s}-p_{L}}{L+1}+\frac{L+1}{4}+\sqrt{A-p_{L}}-\frac{p_{L}-c^{L}}{L+1}\left(1+\frac{1}{2} \frac{L+1}{\sqrt{A-p_{L}}}\right) \\
\frac{\partial \phi_{L}^{3}}{\partial p_{L}} & =2 \sqrt{A-p_{L}}-\frac{p_{L}-c^{L}}{\sqrt{A-p_{L}}} .
\end{aligned}
$$

Evaluating (39)-(41) at autarky prices $p_{s}^{a}=A-1 / 4, p_{L}^{a}=A-L^{2} / 4$ gives

$$
\begin{aligned}
& \left.\frac{\partial \phi_{L}^{1}}{\partial p_{L}}\right|_{\left(p_{s}^{a}, p_{L}^{a}\right)}=\frac{c^{L}+5 L^{2} / 4+L-A}{L+1} \\
& \left.\frac{\partial \phi_{L}^{2}}{\partial p_{L}}\right|_{\left(p_{s}^{a}, p_{L}^{a}\right)}=\frac{L^{3}+L^{2}-(2 L+1)\left(A-L^{2} / 4-c^{L}\right)}{L^{2}+L} \\
& \left.\frac{\partial \phi_{L}^{2}}{\partial p_{L}}\right|_{\left(p_{s}^{a}, p_{L}^{a}\right)}=\frac{2 c^{L}+3 L^{2} / 2-2 A}{L}
\end{aligned}
$$

It is straightforward to show that, for any $c^{L} \leq c_{i}, A>c_{i}+\left(15 L^{2}+12 L\right) / 12$ is sufficient for $\partial \phi_{L}^{j} /\left.\partial p_{L}\right|_{\left(p_{s}^{a}, p_{L}^{a}\right)}<0, j=1,2,3$. Due to $\partial^{2} \phi_{L}^{j} / \partial\left(p_{L}^{j}\right)^{2}<0, \partial^{2} \phi_{L}^{j} / \partial p_{L} \partial p_{s} \geq 0$ and the fact that $\pi_{L}$ is a continuous function in $p_{L}$ (see (45)), it follows that $p_{s} \leq p_{s}^{a}$ and $D_{L}>0$ are only consistent with a free trade equilibrium if $p_{L}<p_{L}^{a}$.

Finally, note that $p_{s}>p_{s}^{a}$ and $p_{L}>p_{L}^{a}$ cannot simultaneously hold in the free trade equilibrium, if $p_{s}^{a}$ and $p_{L}^{a}$ are profit-maximizing prices under autarky. Then, an interior solution with $D_{s}>0$ and $D_{L}>0$ is only consistent with profit maximization of the two final goods producers, if $p_{L}<p_{L}^{a}$ and $p_{s}<p_{s}^{a}$ simultaneously hold in equilibrium. This follows from the analysis above. In such an equilibrium, prices are given by ${ }^{33}$

$$
\begin{aligned}
& p_{s}=\frac{c^{L}+2 c^{s}}{3}+\frac{(5 L+7)(L+1)}{12}, \\
& p_{L}=\frac{2 c^{L}+c^{s}}{3}+\frac{(7 L+5)(L+1)}{12} .
\end{aligned}
$$

\footnotetext{
${ }^{33} p_{s}<p_{s}^{a}=A-1 / 4$ and $p_{L}<p_{L}^{a}=A-L^{2} / 4$ can be shown by using $c^{s} \leq c_{i}$ and $c^{L} \leq c_{i}$ together with $A>c_{i}+\left(15 L^{2}+12 L\right) / 12$.
} 
(These prices are obtained by setting (39) and (49) equal to zero. Second-order conditions for profit maxima are fulfilled, due to $\partial^{2} \phi_{s}^{1} / \partial p_{s}^{2}<0$ and $\partial^{2} \phi_{L}^{1} / \partial p_{L}^{2}<0$.) Using (55) and (56) in (10)-(14) gives

$$
\begin{aligned}
D_{s} & =x_{m}=\frac{c^{L}-c^{s}}{3(L+1)}+\frac{5 L+7}{12} \\
D_{L} & =L+1-x_{m}=\frac{c^{s}-c^{L}}{3(L+1)}+\frac{7 L+5}{12}
\end{aligned}
$$

so that an interior solution with $D_{s}>0$ and $D_{L}>0$ requires

$$
\left(c^{L}-c^{s}\right) \in\left(-\frac{(5 L+7)(L+1)}{4}, \frac{(7 L+5)(L+1)}{4}\right) .
$$

\section{Step (ii): Price setting and corner solutions:}

There are two candidates for corner solutions, namely $D_{s}=0$ and $D_{L}=0$. An interior solution with $D_{s}>0$ is not compatible with profit maximization of the two final goods producers, according to $(57)$, if $c^{L} \leq c^{s}-(5 L+7)(L+1) / 4$. In this case, equilibrium prices fulfill ${ }^{34} p_{L}=p_{s}-(L+3)(L+1) / 4$ and $p_{s} \leq c^{s}$ so that $x_{m}=0$, according to (10), and, therefore, $D_{L}=L+1, D_{s}=0$. In contrast, if $c^{L} \geq c^{s}+(7 L+5)(L+1) / 4$, an interior solution with $D_{L}>0$ is not compatible with profit maximization of the two final goods producers, according to (58). In this case, equilibrium prices fulfill $p_{s}=$ $p_{L}-(3 L+1)(L+1) / 4$ and $p_{L} \leq c^{L}$ so that $x_{m}=L+1$, according to (10), and, therefore, $D_{s}=x_{m}=L+1, D_{L}=0$.

According to steps (i) and (ii) the following holds in the free trade equilibrium. Demand for final output produced in the two countries is given by $D_{s}=x_{m}$ and $D_{L}=$ $L+1-x_{m}$, respectively, so that $D_{s}+D_{L}=L+1$. Together with (15) and (16) this implies $\pi_{s}=\left(p_{s}-c^{s}\right) x_{m}\left(p_{s}, p_{L}\right)$ and $\pi_{L}=\left(p_{L}-c^{L}\right)\left(L+1-x_{m}\left(p_{s}, p_{L}\right)\right)$ and, therefore, establishes Lemma 1.

\footnotetext{
${ }^{34}$ Although the final goods producer in country $s$ is indifferent between all $p_{s} \geq c^{s}$ if $D_{s}=0$, prices $p_{s}>c^{s}$ are not consistent with an equilibrium. Moreover, the price equilibrium is not unique if $c^{L}<$ $c^{s}-(5 L+7)(L+1) / 4$. In this case, not only $p_{s}=c^{s}$ but also some $p_{s}<c^{s}$ are consistent with an equilibrium.
} 


\section{Appendix B: Formal derivation of the welfare effects of trade liberalization}

Assumption 2 is considered throughout Appendix B.

The case of technical exclusion of international outsourcing: $t>4\left(c_{i}-c_{u}\right) /(L+1)^{2}$

The proof is organized in three parts.

Part (i): Consider $c_{i}-c_{u}<(17 L-5)(L+1) / 4$. Then, $x_{m}^{*}>1$ follows, according to (24). The welfare change in the small economy is given by $\Delta W_{s}=\int_{1}^{x_{m}^{*}}\left[p_{s}^{*}-c_{i}\right] d b>0$ and welfare changes in $L$ are given by

$$
\Delta W_{L}=\int_{1}^{x_{m}^{*}}\left[p_{L}^{a}(b)-p_{s}^{*}(b)\right] d b-\int_{1}^{x_{m}^{*}}\left[p_{L}^{a}-c_{u}\right] d b
$$

where $p_{L}^{a}(b)=p_{L}^{a}+[b-(1+L / 2)]^{2}$ and $p_{s}^{*}(b)=p_{s}^{*}+[b-1 / 2]^{2} \cdot p_{L}^{a}=A-L^{2} / 4$, according to Proposition 1. Moreover, substituting $c_{i}=c^{s}$ and, according to (23), $\rho^{L *}=c^{L}$ in (19) gives

$$
p_{s}^{*}=\left\{\begin{array}{ccc}
\frac{5 c_{i}+c_{u}}{6}+\frac{(17 L+19)(L+1)}{24} & \text { if } & c_{i} \in\left[\underline{c_{i}}, \widetilde{c}_{i}\right) \\
c_{i}+\frac{(5 L+7)(L+1)}{12} & \text { if } \quad & c_{i} \in\left(c_{u}, \underline{c_{i}}\right)
\end{array},\right.
$$

where $\underline{c_{i}}=c_{u}+(7 L+5)(L+1) / 4$, according to $(23)$, and $\widetilde{c_{i}}:=c_{u}+(17 L-5)(L+1) / 4$ are used. Thus, (60) can be rewritten as

$$
\Delta W_{L}=\int_{1}^{x_{m}^{*}}\left[[b-(1+L / 2)]^{2}-[b-1 / 2]^{2}\right] d b-\int_{1}^{x_{m}^{*}} \frac{(5 L+7)(L+1)}{12} d b-\Delta \Psi_{2},
$$

where

$$
\Delta \Psi_{2}:=\left\{\begin{array}{cccc}
\int_{1}^{x_{m}^{*}}\left[\frac{5}{6}\left(c_{i}-c_{u}\right)+\frac{(7 L+5)(L+1)}{24}\right] d b & \text { if } & c_{i} \in\left[\underline{c_{i}}, \widetilde{c_{i}}\right) \\
\int_{1}^{x_{m}^{*}}\left(c_{i}-c_{u}\right) d b & \text { if } & c_{i} \in\left(c_{u}, \underline{c_{i}}\right)
\end{array} .\right.
$$

Using $x_{m}^{*}$, according to (24), and substituting (63) into (62) gives

$$
\Delta W_{L}=\left\{\begin{array}{lll}
-\left(x_{m}^{*}-1\right)\left[\frac{(13 L+15)(L+1)}{16}+\frac{3\left(c_{i}-c_{u}\right)}{4}\right] & \text { if } & c_{i} \in\left[\underline{c_{i}}, \widetilde{c}_{i}\right) \\
-\left(x_{m}^{*}-1\right)\left[\frac{(3 L+5)(L+1)}{8}+\left(c_{i}-c_{u}\right)\right] & \text { if } & c_{i} \in\left(c_{u}, \underline{c_{i}}\right)
\end{array},\right.
$$


and, therefore, $\Delta W_{L}<0$. Finally, $\Delta W=\Delta W_{L}+\Delta W_{s}$ implies

$$
\begin{aligned}
\Delta W & =\int_{1}^{x_{m}^{*}}\left[[b-(1+L / 2)]^{2}-[b-1 / 2]^{2}\right] d b-\int_{1}^{x_{m}^{*}}\left(c_{i}-c_{u}\right) d b \\
& =\left\{\begin{array}{ccc}
-\left(x_{m}^{*}-1\right)\left[\frac{11\left(c_{i}-c_{u}\right)}{12}+\frac{(5 L+7)(L+1)}{48}\right] & \text { if } & c_{i} \in\left[\underline{c_{i}}, \widetilde{c}_{i}\right) \\
\left(x_{m}^{*}-1\right)\left[\frac{L^{2}-1}{24}-\left(c_{i}-c_{u}\right)\right] & \text { if } & c_{i} \in\left(c_{u}, \underline{c_{i}}\right)
\end{array} .\right.
\end{aligned}
$$

Since $c_{i}-c_{u}<(L-1)(L+1) / 24$ implies $c_{i}<\underline{c_{i}}$, it is straightforward to show that $\Delta W \gtreqless 0$ if $c_{i}-c_{u} \lesseqgtr(L-1)(L+1) / 24$.

Part (ii): If $c_{i}-c_{u}=(17 L-5)(L+1) / 4$, then the marginal consumer is located at $x_{m}^{*}=1$, according to (24), so that welfare in both economies and, therefore, also overall world welfare are unaffected by free trade, i.e., $\Delta W=\Delta W_{k}=0, k=s, L$.

Part (iii): Consider $c_{i}-c_{u}>(17 L-5)(L+1) / 4$. Then, $x_{m}^{*}<1$ holds, according to (24), so that trade liberalization leads to a welfare gain in the large economy, which is given by $\Delta W_{L}=\int_{x_{m}^{*}}^{1}\left[p_{L}^{*}-c_{u}\right] d b>0$. Welfare changes in $s$ are given by

$$
\Delta W_{s}=\int_{x_{m}^{*}}^{1}\left[p_{s}^{a}(b)-p_{L}^{*}(b)\right] d b-\int_{x_{m}^{*}}^{1}\left[p_{s}^{a}-c_{i}\right] d b,
$$

where $p_{s}^{a}(b)=p_{s}^{a}+[b-1 / 2]^{2}$ and $p_{L}^{*}(b)=p_{L}^{*}+[b-(1+L / 2)]^{2} \cdot p_{s}^{a}=A-1 / 4$, according to Proposition 1. Moreover, substituting $c_{i}=c^{s}$ and, according to (23), $\rho^{L *}=c^{L}$ in (20) gives

$$
p_{L}^{*}=\left\{\begin{array}{ccc}
c_{i}-\frac{(L+3)(L+1)}{4} & \text { if } & c_{i}>\overline{c_{i}} \\
\frac{2 c_{i}+c_{u}}{3}+\frac{(7 L+5)(L+1)}{6} & \text { if } & c_{i} \in\left(\widetilde{c_{i}}, \overline{c_{i}}\right]
\end{array},\right.
$$

where $\overline{c_{i}}=c_{u}+(17 L+19)(L+1) / 4$, according to $(23)$, and $\widetilde{c_{i}}=c_{u}+(17 L-5)(L+1) / 4$ are used. Hence, (66) can be transformed into

$$
\Delta W_{s}=\int_{x_{m}^{*}}^{1}\left[[b-1 / 2]^{2}-[b-(1+L / 2)]^{2}\right] d b-\int_{x_{m}^{*}}^{1} \frac{(7 L+5)(L+1)}{12} d b+\Delta \Psi_{3},
$$

where

$$
\Delta \Psi_{3}:=\left\{\begin{array}{ccc}
\int_{x_{m}^{*}}^{1} \frac{(5 L+7)(L+1)}{6} d b & \text { if } & c_{i}>\overline{c_{i}} \\
\int_{x_{m}^{*}}^{1}\left[\frac{c_{i}-c_{u}}{3}-\frac{(7 L+5)(L+1)}{12}\right] d b & \text { if } & c_{i} \in\left(\widetilde{c_{i}}, \overline{c_{i}}\right]
\end{array} .\right.
$$


Using $x_{m}^{*}$, according to (24) and substituting (69) in (68) implies

$$
\Delta W_{s}=\left\{\begin{array}{ccc}
\frac{L+1}{2} & \text { if } & c_{i}>\overline{c_{i}} \\
\left(1-x_{m}^{*}\right)\left[\frac{\left(c_{i}-c_{u}\right)}{4}-\frac{(17 L+11)(L+1)}{16}\right] & \text { if } & c_{i} \in\left(\widetilde{c_{i}}, \overline{c_{i}}\right]
\end{array} .\right.
$$

From (70) it is obvious that $\Delta W_{s} \gtreqless 0$ if $c_{i}-c_{u} \gtreqless(17 L+11)(L+1) / 4$. (Remember that $c_{i}-c_{u}>(17 L-5)(L+1) / 4$ holds. $)$ Finally, $\Delta W=\Delta W_{s}+\Delta W_{L}$ is given by

$$
\begin{aligned}
\Delta W & =\int_{x_{m}^{*}}^{1}\left[[b-1 / 2]^{2}-[b-(1+L / 2)]^{2}\right] d b+\int_{x_{m}^{*}}^{1}\left(c_{i}-c_{u}\right) d b \\
& =\left\{\begin{array}{ccc}
\left(c_{i}-c_{u}\right)-\frac{(L+1)^{2}}{4} & \text { if } & c_{i}>\overline{c_{i}} \\
\left(1-x_{m}^{*}\right)\left[\frac{11\left(c_{i}-c_{u}\right)}{12}+\frac{(5 L+7)(L+1)}{48}\right] & \text { if } & c_{i} \in\left(\widetilde{c_{i}}, \overline{c_{i}}\right]
\end{array},\right.
\end{aligned}
$$

with $\Delta W>0$. This completes the proof.

The case of international outsourcing: $t \leq 4\left(c_{i}-c_{u}\right) /(L+1)^{2}$

The proof is organized in three parts.

Part (i): Consider $t<\frac{17 L-5}{L+1}$. Then, $x_{m}^{*}>1$ holds, according to (27), so that trade liberalization leads to $\Delta W_{s}=\int_{1}^{x_{m}^{*}}\left[p_{s}^{*}-c_{i}\right] d b>0$. Thereby, $\rho^{s, d}=c_{i}$ has been used. Welfare changes in $L$ are given by

$$
\Delta W_{L}=\int_{1}^{x_{m}^{*}}\left[p_{L}^{a}(b)-p_{s}^{*}(b)\right] d b-\int_{1}^{x_{m}^{*}}\left[p_{L}^{a}-\rho^{s *}\right] d b+\int_{0}^{1}\left[\rho^{s *}-c_{u}\right] d b,
$$

where $p_{L}^{a}(b)=p_{L}^{a}+[b-(1+L / 2)]^{2}, p_{s}^{*}(b)=p_{s}^{*}+[b-1 / 2]^{2}, \rho^{s *}=c_{i}-t\left(\frac{L+1}{2}\right)^{2}$ and $p_{L}^{a}=A-L^{2} / 4$. Substituting $c_{i}=\rho^{s, d}=c^{s}$ and, according to (26), $\rho^{L *}=c^{L}$ in (19) implies

$$
p_{s}^{*}=\left\{\begin{array}{cl}
c_{i}-t \frac{(L+1)^{2}}{24}+\frac{(17 L+19)(L+1)}{24} & \text { if } t \in B_{1} \\
c_{i}+\frac{(5 L+7)(L+1)}{12} & \text { if } t \in B_{2}
\end{array},\right.
$$

with $B_{1}:=\left[\frac{7 L+5}{L+1}, \frac{17 L-5}{L+1}\right)$ and $B_{2}:=\left(0, \frac{7 L+5}{L+1}\right)$. Note that $(72)$ accounts for the fact that trade liberalization leads to profits in the amount of $\int_{0}^{x_{m}^{*}}\left[\rho^{s *}-c_{u}\right] d b$ from intermediate goods exports to the final goods producer located in country $s$. Straightforward calculations imply

$$
\Delta W_{L}=\int_{1}^{x_{m}^{*}}\left[[b-(1+L / 2)]^{2}-[b-1 / 2]^{2}\right] d b-\int_{1}^{x_{m}^{*}} \frac{(5 L+7)(L+1)}{12} d b-\Delta \Psi_{4},
$$


according to (72). Thereby,

$$
\Delta \Psi_{4}:=\left\{\begin{array}{cl}
\int_{1}^{x_{m}^{*}}\left[\frac{(7 L+5)(L+1)}{24}+5 t \frac{(L+1)^{2}}{24}\right] d b-\left(c_{i}-c_{u}\right)+t\left(\frac{L+1}{2}\right)^{2} & \text { if } t \in B_{1} \\
\int_{1}^{x_{m}^{*}} t\left(\frac{L+1}{2}\right)^{2} d b-\left(c_{i}-c_{u}\right)+t\left(\frac{L+1}{2}\right)^{2} & \text { if } t \in B_{2}
\end{array}\right.
$$

has been used. Using $x_{m}^{*}$, according to (27), and substituting (75) in (74) gives

$$
\Delta W_{L}=\left\{\begin{array}{lll}
-\left(x_{m}^{*}-1\right)\left[\frac{(13 L+15)(L+1)}{16}+3 t \frac{(L+1)^{2}}{16}\right]+\left(c_{i}-c_{u}\right)-t\left(\frac{L+1}{2}\right)^{2} & \text { if } & t \in B_{1} \\
-\left(x_{m}^{*}-1\right)\left[\frac{[(3 L+5)](L+1)}{8}+t\left(\frac{L+1}{2}\right)^{2}\right]+\left(c_{i}-c_{u}\right)-t\left(\frac{L+1}{2}\right)^{2} & \text { if } \quad t \in B_{2}
\end{array} .\right.
$$

Since $t \leq 4\left(c_{i}-c_{u}\right) /(L+1)^{2}$, it is straightforward to show that the sign of $\Delta W_{L}$ is ambiguous. Using $\Delta W=\Delta W_{s}+\Delta W_{L}$ implies

$$
\begin{aligned}
& \Delta W=\int_{1}^{x_{m}^{*}}\left[[b-(1+L / 2)]^{2}-[b-1 / 2]^{2}\right] d b-\int_{1}^{x_{m}^{*}}\left(c_{i}-\rho^{s, *}\right) d b+\int_{0}^{1}\left[\rho^{s, *}-c_{u}\right] d b \\
& =\left\{\begin{array}{rll}
-\left(x_{m}^{*}-1\right)\left[\frac{(5 L+7)(L+1)}{48}+11 t \frac{(L+1)^{2}}{48}\right]+\left(c_{i}-c_{u}\right)-t\left(\frac{L+1}{2}\right)^{2} & \text { if } & t \in B_{1} \\
\left(x_{m}^{*}-1\right)\left[\frac{(L-1)(L+1)}{24}-t\left(\frac{L+1}{2}\right)^{2}\right]+\left(c_{i}-c_{u}\right)-t\left(\frac{L+1}{2}\right)^{2} & \text { if } \quad t \in B_{2}
\end{array}\right.
\end{aligned}
$$

From (77) it is obvious that the sign of $\Delta W$ is ambiguous. However, $t<(L-1) /[6(L+1)]$ is sufficient for $\Delta W>0 .{ }^{35}$ Thereby, $(L-1) /[6(L+1)]<(7 L+5) /(L+1)$ has been considered.

Part (ii): Note that there is no trade of the consumption good, if $t=(17 L-5) /(L+1)$, according to (27). Thus, $\rho^{s, d}=\rho^{s *}+t(L+1)^{2} / 4=c_{i}$ implies that welfare in country $s$ is not affected by trade liberalization. Due to exports of the intermediate good, welfare changes in $L$ are given by $\Delta W_{L}=\int_{0}^{1}\left[\rho^{s *}-c_{u}\right] d b$, which are strictly positive if $t<$ $4\left(c_{i}-c_{u}\right) /(L+1)^{2}$. In contrast, welfare in $L$ is unchanged, if $t=4\left(c_{i}-c_{u}\right) /(L+1)^{2}$. Overall world welfare changes are determined by welfare changes in $L$, i.e., $\Delta W=\Delta W_{L}$, since $\Delta W_{s}=0$.

Part (iii): Consider $t>(17 L-5) /(L+1)$. Then, $x_{m}^{*}<1$ holds, according to (27), so that trade liberalization leads to a welfare gain in country $L$ that is given by $\Delta W_{L}=$ $\int_{x_{m}^{*}}^{1}\left[p_{L}^{*}-c_{u}\right] d b+\int_{0}^{x_{m}^{*}}\left[\rho^{s *}-c_{u}\right] d b>0$. Thereby, $\int_{0}^{x_{m}^{*}}\left[\rho^{s *}-c_{u}\right] d b$ are profits obtained

\footnotetext{
${ }^{35}$ Moreover, $t>\frac{L-1}{6(L+1)}$ and $t=4 \frac{c_{i}-c_{u}}{(L+1)^{2}}$ are sufficient for $\Delta W<0$.
} 
from intermediate goods exports to country $s$. Use $\rho^{s, d}=c_{i}$. Then, welfare changes in country $s$ are given by

$$
\Delta W_{s}=\int_{x_{m}^{*}}^{1}\left[p_{s}^{a}(b)-p_{L}^{*}(b)\right] d b-\int_{x_{m}^{*}}^{1}\left[p_{s}^{a}-c_{i}\right] d b,
$$

where $p_{s}^{a}(b)=p_{s}^{a}+[b-1 / 2]^{2}$ and $p_{L}^{*}(b)=p_{L}^{*}+[b-(1+L / 2)]^{2} \cdot p_{s}^{a}=A-1 / 4$, according to Proposition 1. Moreover, substituting $c_{i}=\rho^{s, d}=c^{s}$ and, according to (26), $\rho^{L *}=c^{L}$ in (20) gives

$$
p_{L}^{*}=\left\{\begin{array}{ccc}
c_{i}-\frac{(L+3)(L+1)}{4} & \text { if } & t>\frac{17 L+19}{L+1} \\
c_{i}-t \frac{(L+1)^{2}}{12}+\frac{(7 L+5)(L+1)}{6} & \text { if } \quad t \in B_{3}
\end{array},\right.
$$

with $B_{3}:=\left(\frac{17 L-5}{L+1}, \frac{17 L+19}{L+1}\right]$. (78) can be rewritten as

$$
\Delta W_{s}=\int_{x_{m}^{*}}^{1}\left[[b-1 / 2]^{2}-[b-(1+L / 2)]^{2}\right] d b-\int_{x_{m}^{*}}^{1} \frac{(7 L+5)(L+1)}{12} d b-\Delta \Psi_{5} .
$$

Thereby,

$$
\Delta \Psi_{5}:=\left\{\begin{array}{ccc}
-\int_{x_{m}^{*}}^{1} \frac{(5 L+7)(L+1)}{6} d b & \text { if } & t>\frac{17 L+19}{L+1} \\
\int_{x_{m}^{*}}^{1}\left[\frac{(7 L+5)(L+1)}{12}-t \frac{(L+1)^{2}}{12}\right] d b & \text { if } & t \in B_{3}
\end{array}\right.
$$

has been used. In view of $(27),(80)$ and (81), one obtains

$$
\Delta W_{s}=\left\{\begin{array}{ccc}
\frac{L+1}{2} & \text { if } & t>\frac{17 L+19}{L+1} \\
-\left(1-x_{m}^{*}\right)\left[\frac{(17 L+11)(L+1)}{16}-t \frac{(L+1)^{2}}{16}\right] & \text { if } & t \in B_{3}
\end{array} .\right.
$$

Thus, $\Delta W_{s} \gtreqless 0$ if $t \gtreqless(17 L+11) /(L+1)$. (Remember that $t>(17 L-5) /(L+1)$ holds.) Finally, using $\Delta W=\Delta W_{s}+\Delta W_{L}$ gives

$$
\begin{aligned}
& \Delta W=\int_{x_{m}^{*}}^{1}\left[[b-1 / 2]^{2}-[b-(1+L / 2)]^{2}\right] d b+\int_{x_{m}^{*}}^{1}\left(c_{i}-c_{u}\right) d b+\int_{0}^{x_{m}^{*}}\left[\rho^{s, *}-c_{u}\right] d b \\
& =\left\{\begin{array}{ccc}
\left(c_{i}-c_{u}\right)-\left(\frac{L+1}{2}\right)^{2} & \text { if } \quad t>\frac{17 L+19}{L+1} \\
\left(1-x_{m}^{*}\right)\left[\frac{(5 L+7)(L+1)}{48}+\left(c_{i}-c_{u}\right)-t \frac{(L+1)^{2}}{48}\right. & \\
\left.+\frac{x_{m}^{*}}{1-x_{m}^{*}}\left(\left(c_{i}-c_{u}\right)-t\left(\frac{L+1}{2}\right)^{2}\right)\right] & \text { if } \quad t \in B_{3}
\end{array} .\right.
\end{aligned}
$$

Thereby, $\Delta W>0$ holds since $c_{i}-c_{u} \geq t(L+1)^{2} / 4$ and $t(>(17 L-5) /(L+1))>1$. This completes the proof. 


\section{References}

Anderson, James E. and Eric van Wincoop (2004), Trade Costs, preliminary draft, in preparation for the Journal of Economic Literature.

Anderson, Simon (1987), Spatial Competition and Price Leadership, International Journal of Industrial Organization 5, 369-398.

Behrens, Kristian, Carl Gaigne, Gianmarco I.P. Ottaviano, and Jacques-F. Thisse (2003), Interegional and International Trade: Seventy Years after Ohlin, CEPR Discussion Paper 4065.

Beissinger, Thomas and Hartmut Egger (2004), Dynamic Wage Bargaining if Benefits Are Tied to Individual Wages, Oxford Economic Papers 56, 2004, 437-460.

Burda, Michael C. and Barbara Dluhosch (2002), Cost Competition, Fragmentation and Globalization, Review of International Economics 10, 424-41.

Coase, Ronald H. (1937), The Nature of the Firm, Economica (NS) 4, 386-405.

d'Aspremont, Claude, Jean J. Gabszewicz, and Jacques-François Thisse (1979), On Hotelling's "Stability in Competition", Econometrica 47, 1145-1150.

Egger, Hartmut and Peter Egger (2003), Outsourcing and Skill-Specific Employment in a Small Economy: Austria after the Fall of the Iron Curtain, Oxford Economic Papers 55, 625-643.

Feenstra, Robert C. (1998), Integration of Trade and Disintegration of Production. Journal of Economic Perspectives 12, 31-50.

Feenstra, Robert C. and Gordon H. Hanson (1996), Globalization, Outsourcing and Wage Inequality, American Economic Review 86, 240-245.

Feenstra Robert C. and Gordon H. Hanson (1999), The Impact of Outsourcing and High-Technology Capital on Wages: Estimates for the United States, 1979-1990, Quarterly Journal of Economics 114, 907-940. 
Feenstra, Robert C. and Gordon H. Hanson (2001), Global Production Sharing and Rising Inequality: A Survey of Trade and Wages, in Kwan Choi and James Harrigan (eds.), Handbook of International Trade, Basil Blackwell, forthcoming.

Grossman Gene M. and Elhanan Helpman (2002a), Integration versus Outsourcing in Industry Equilibrium, Quarterly Journal of Economics 117, 85-120.

Grossman Gene M. and Elhanan Helpman (2002b), Outsourcing in a Global Economy, NBER Working Paper 8728, forthcoming in the Review of Economic Studies.

Hamoudi, Hamid and Maria J. Moral (2003), Equilibrium Existence in the Linear Model: Concave versus Convex Transportation Costs, unpublished manuscript, Universidad Europea de Madrid.

Head, Keith and Thierry Mayer (2004), The Empirics of Agglomeration and Trade, forthcoming in the Handbook of Regional and Urban Economics..

Helsley, Robert W. and William C. Strange (2004), Agglomeration, Opportunism and the Organization of Production, CUER Working Paper 03-02.

Hummels, David, Jun Ishii, and Kei-Mu Yi (2001), The Nature and Growth of Vertical Specialization in World Trade, Journal of International Economics 54, 75-96.

Jones, Ronald W. (2000) Globalization and the Theory of Input Trade, MIT Press, Cambridge.

Jones, Ronald W. and Henryk Kierzkowski (2001), A Framework for Fragmentaton, in Sven W. Arndt and Henryk Kierzkowski, eds., Fragmentation: New Production Patterns in the World Economy, Oxford University Press, Oxford, 17-34.

Kohler, Wilhelm (2004), International Outsourcing and Factor Prices With Multistage Production, Economic Journal 114, C166-C185.

Kumar, Krishna B., Raghuram G. Rajan and Luigi Zingales (1999), What Determines Firm Size?, NBER Working Paper 7208. 
Layard, Richard and Stephen Nickell (1990), Is Unemployment Lower if Unions Bargain over Employment?, Quarterly Journal of Economics 105,. 773-87.

Ludema, Rodney D. and Ian Wooton (2000), Economic Geography and the Fiscal Effects of Regional Integration, Journal of International Economics 52, 331-357.

McLaren, John (2000), "Globalization" and Vertical Structure, American Economic Review $90,1239-1254$.

Ohlin, Bertil (1933) Interregional and International Trade. Cambridge, MA: Haravrd University Press. Revised version published in 1968.

Osborne, Martin J. and Carolyn Pitchik (1986), The Nature of Equilibrium in a Locational Model, International Economic Review 27, 223-237.

Rietveld, Piet and Roger Vickermann (2004), Transport in Regional Science: The Death of Distance is Premature, Papers in Regional Science 83, 229-248.

Shachmurove, Yochanan and Uriel Spiegel (1995), On Nations' Size and Transportation Costs, Review of International Economics 3, 235-243.

Tharakan, Joe (2001), Revisiting "On Nations Size' and Transportation Costs", CORE Discussion Paper 2001/32.

Tharakan, Joe and Jacques-François Thisse (2002), The Importance of Being Small. Or When Countries are Areas and Not Points, Regional Science and Urban Economics $32,381-408$.

Wong, Kar-yiu, 1995, International Trade in Goods and Factor Mobility. Cambridge, Mass: MIT Press. 


\section{CESifo Working Paper Series}

(for full list see www.cesifo.de)

1285 Luis H. R. Alvarez and Erkki Koskela, Does Risk Aversion Accelerate Optimal Forest Rotation under Uncertainty?, September 2004

1286 Giorgio Brunello and Maria De Paola, Market Failures and the Under-Provision of Training, September 2004

1287 Sanjeev Goyal, Marco van der Leij and José Luis Moraga-González, Economics: An Emerging Small World?, September 2004

1288 Sandro Maffei, Nikolai Raabe and Heinrich W. Ursprung, Political Repression and Child Labor: Theory and Empirical Evidence, September 2004

1289 Georg Götz and Klaus Gugler, Market Concentration and Product Variety under Spatial Competition: Evidence from Retail Gasoline, September 2004

1290 Jonathan Temple and Ludger Wößmann, Dualism and Cross-Country Growth Regressions, September 2004

1291 Ravi Kanbur, Jukka Pirttilä and Matti Tuomala, Non-Welfarist Optimal Taxation and Behavioral Public Economics, October 2004

1292 Maarten C. W. Janssen, José Luis Moraga-González and Matthijs R. Wildenbeest, Consumer Search and Oligopolistic Pricing: An Empirical Investigation, October 2004

1293 Kira Börner and Christa Hainz, The Political Economy of Corruption and the Role of Financial Institutions, October 2004

1294 Christoph A. Schaltegger and Lars P. Feld, Do Large Cabinets Favor Large Governments? Evidence from Swiss Sub-Federal Jurisdictions, October 2004

1295 Marc-Andreas Mündler, The Existence of Informationally Efficient Markets When Individuals Are Rational, October 2004

1296 Hendrik Jürges, Wolfram F. Richter and Kerstin Schneider, Teacher Quality and Incentives: Theoretical and Empirical Effects of Standards on Teacher Quality, October 2004

1297 David S. Evans and Michael Salinger, An Empirical Analysis of Bundling and Tying: Over-the-Counter Pain Relief and Cold Medicines, October 2004

1298 Gershon Ben-Shakhar, Gary Bornstein, Astrid Hopfensitz and Frans van Winden, Reciprocity and Emotions: Arousal, Self-Reports, and Expectations, October 2004 
1299 B. Zorina Khan and Kenneth L. Sokoloff, Institutions and Technological Innovation During Early Economic Growth: Evidence from the Great Inventors of the United States, 1790 - 1930, October 2004

1300 Piero Gottardi and Roberto Serrano, Market Power and Information Revelation in Dynamic Trading, October 2004

1301 Alan V. Deardorff, Who Makes the Rules of Globalization?, October 2004

1302 Sheilagh Ogilvie, The Use and Abuse of Trust: Social Capital and its Deployment by Early Modern Guilds, October 2004

1303 Mario Jametti and Thomas von Ungern-Sternberg, Disaster Insurance or a Disastrous Insurance - Natural Disaster Insurance in France, October 2004

1304 Pieter A. Gautier and José Luis Moraga-González, Strategic Wage Setting and Coordination Frictions with Multiple Applications, October 2004

1305 Julia Darby, Anton Muscatelli and Graeme Roy, Fiscal Federalism, Fiscal Consolidations and Cuts in Central Government Grants: Evidence from an Event Study, October 2004

1306 Michael Waldman, Antitrust Perspectives for Durable-Goods Markets, October 2004

1307 Josef Honerkamp, Stefan Moog and Bernd Raffelhüschen, Earlier or Later: A General Equilibrium Analysis of Bringing Forward an Already Announced Tax Reform, October 2004

1308 M. Hashem Pesaran, A Pair-Wise Approach to Testing for Output and Growth Convergence, October 2004

1309 John Bishop and Ferran Mane, Educational Reform and Disadvantaged Students: Are They Better Off or Worse Off?, October 2004

1310 Alfredo Schclarek, Consumption and Keynesian Fiscal Policy, October 2004

1311 Wolfram F. Richter, Efficiency Effects of Tax Deductions for Work-Related Expenses, October 2004

1312 Franco Mariuzzo, Patrick Paul Walsh and Ciara Whelan, EU Merger Control in Differentiated Product Industries, October 2004

1313 Kurt Schmidheiny, Income Segregation and Local Progressive Taxation: Empirical Evidence from Switzerland, October 2004

1314 David S. Evans, Andrei Hagiu and Richard Schmalensee, A Survey of the Economic Role of Software Platforms in Computer-Based Industries, October 2004

1315 Frank Riedel and Elmar Wolfstetter, Immediate Demand Reduction in Simultaneous Ascending Bid Auctions, October 2004 
1316 Patricia Crifo and Jean-Louis Rullière, Incentives and Anonymity Principle: Crowding Out Toward Users, October 2004

1317 Attila Ambrus and Rossella Argenziano, Network Markets and Consumers Coordination, October 2004

1318 Margarita Katsimi and Thomas Moutos, Monopoly, Inequality and Redistribution Via the Public Provision of Private Goods, October 2004

1319 Jens Josephson and Karl Wärneryd, Long-Run Selection and the Work Ethic, October 2004

1320 Jan K. Brueckner and Oleg Smirnov, Workings of the Melting Pot: Social Networks and the Evolution of Population Attributes, October 2004

1321 Thomas Fuchs and Ludger Wößmann, Computers and Student Learning: Bivariate and Multivariate Evidence on the Availability and Use of Computers at Home and at School, November 2004

1322 Alberto Bisin, Piero Gottardi and Adriano A. Rampini, Managerial Hedging and Portfolio Monitoring, November 2004

1323 Cecilia García-Peñalosa and Jean-François Wen, Redistribution and Occupational Choice in a Schumpeterian Growth Model, November 2004

1324 William Martin and Robert Rowthorn, Will Stability Last?, November 2004

1325 Jianpei Li and Elmar Wolfstetter, Partnership Dissolution, Complementarity, and Investment Incentives, November 2004

1326 Hans Fehr, Sabine Jokisch and Laurence J. Kotlikoff, Fertility, Mortality, and the Developed World's Demographic Transition, November 2004

1327 Adam Elbourne and Jakob de Haan, Asymmetric Monetary Transmission in EMU: The Robustness of VAR Conclusions and Cecchetti's Legal Family Theory, November 2004

1328 Karel-Jan Alsem, Steven Brakman, Lex Hoogduin and Gerard Kuper, The Impact of Newspapers on Consumer Confidence: Does Spin Bias Exist?, November 2004

1329 Chiona Balfoussia and Mike Wickens, Macroeconomic Sources of Risk in the Term Structure, November 2004

1330 Ludger Wößmann, The Effect Heterogeneity of Central Exams: Evidence from TIMSS, TIMSS-Repeat and PISA, November 2004

1331 M. Hashem Pesaran, Estimation and Inference in Large Heterogeneous Panels with a Multifactor Error Structure, November 2004

1332 Maarten C. W. Janssen, José Luis Moraga-González and Matthijs R. Wildenbeest, A Note on Costly Sequential Search and Oligopoly Pricing, November 2004 
1333 Martin Peitz and Patrick Waelbroeck, An Economist's Guide to Digital Music, November 2004

1334 Biswa N. Bhattacharyay and Prabir De, Promotion of Trade, Investment and Infrastructure Development between China and India: The Case of Southwest China and East and Northeast India, November 2004

1335 Lutz Hendricks, Why Does Educational Attainment Differ Across U.S. States?, November 2004

1336 Jay Pil Choi, Antitrust Analysis of Tying Arrangements, November 2004

1337 Rafael Lalive, Jan C. van Ours and Josef Zweimueller, How Changes in Financial Incentives Affect the Duration of Unemployment, November 2004

1338 Robert Woods, Fiscal Stabilisation and EMU, November 2004

1339 Rainald Borck and Matthias Wrede, Political Economy of Commuting Subsidies, November 2004

1340 Marcel Gérard, Combining Dutch Presumptive Capital Income Tax and US Qualified Intermediaries to Set Forth a New System of International Savings Taxation, November 2004

1341 Bruno S. Frey, Simon Luechinger and Alois Stutzer, Calculating Tragedy: Assessing the Costs of Terrorism, November 2004

1342 Johannes Becker and Clemens Fuest, A Backward Looking Measure of the Effective Marginal Tax Burden on Investment, November 2004

1343 Heikki Kauppi, Erkki Koskela and Rune Stenbacka, Equilibrium Unemployment and Capital Intensity Under Product and Labor Market Imperfections, November 2004

1344 Helge Berger and Till Müller, How Should Large and Small Countries Be Represented in a Currency Union?, November 2004

1345 Bruno Jullien, Two-Sided Markets and Electronic Intermediaries, November 2004

1346 Wolfgang Eggert and Martin Kolmar, Contests with Size Effects, December 2004

1347 Stefan Napel and Mika Widgrén, The Inter-Institutional Distribution of Power in EU Codecision, December 2004

1348 Yin-Wong Cheung and Ulf G. Erlandsson, Exchange Rates and Markov Switching Dynamics, December 2004

1349 Hartmut Egger and Peter Egger, Outsourcing and Trade in a Spatial World, December 2004 